\title{
The Structures of Depictive and Resultative Constructions in Chinese $^{*}$
}

\author{
Niina Zhang \\ ZAS \\ zhang@zas.gwz-berlin.de
}

\begin{abstract}
In this paper I firstly argue that secondary predicates are complement of $\mathrm{v}$, and $\mathrm{v}$ is overtly realized by Merge or Move in secondary predication in Chinese. The former option derives the de-construction, whereas the latter option derives the V-V construction. Secondly, I argue that resultatives are hosted by complement vPs, whereas depictives are hosted by adjunct vPs. This complement-adjunct asymmetry accounts for a series of syntactic properties of secondary predication in Chinese: the position of a secondary predicate with respect to the verb of the primary predicate, the co-occurrence patterns of secondary predicates, the hierarchy of depictives, the control and ECM properties of resultative constructions, and the locality constraint on the integration of secondary predicates into the structure of primary predication. Thirdly, I argue that the surface position of $d e$ is derived by a PF operation which attaches $d e$ to the right of the leftmost verbal lexical head of the construction. Finally, I argue that in the $\mathrm{V}-\mathrm{V}$ resultative construction, the assumed successive head-raising may account for the possible subject-oriented reading of the resultative predicate, and that the head raising out of the lower vP accounts for the possible non-specific reading of the subject of the resultative predicate.
\end{abstract}

\section{Introduction}

This paper discusses the syntactic structures of depictive and resultative constructions in Chinese. According to Halliday (1967: 63), resultatives describe a resultant state which is caused by the action denoted in the primary predication, whereas depictives describe the state of their subject at the time when the action denoted by the primary predication occurs. In Chinese, depictives precede whereas resultatives follow the verb of primary predication (Vpri hence), respectively. In (1) the resultatives follow the Vpri $d a$ 'beat', whereas in (2) the depictives precede the Vpris zhuo 'catch' and he 'drink'. Both resultative and depictive constructions are represented in either the de-construction, where the functional word de occurs, or the $\mathrm{V}-\mathrm{V}$ construction, where the lexical head of the secondary predicate is adjacent to Vpri. The a-sentences in (1) and (2) are in the V-V construction, whereas the b-sentences there are in the de-construction. We can also see that in the resultative de construction, de is right-adjacent to the Vpri, as in (1b); whereas in the depictive de construction, de is rightadjacent to the depictive, as in (2b). ${ }^{2}$

\footnotetext{
* For helpful comments on this paper, I am grateful to Chris Wilder, Anatoli Strigin, and Gerhard Jäger. All remaining errors are mine.

1 The abbreviations used in the Chinese examples are: EXP: experience aspect, PRF: perfect aspect, PROG: progressive aspect, BA: causative particle, CL: classifier, MOD: modification marker.

${ }^{2}$ Pre-Vpri de and post-Vpri de are graphically different in Mandarin Chinese and phonologically different in some Chinese dialects. However, the different phonological or written forms do not mean that they are syntactically different. The different forms can be viewed as positional variants of the same category, as we often see in phonology. Crucially, the two forms of de occur in non-primary predication only, and they themselves do not have any semantic features to distinguish each other.
} 
a. Wusong da si le laohu.

(resultative, $\mathrm{V}-\mathrm{V}$ )

Wusong beat die PRF tiger

'Wusong beat the tiger so that it died.'

b. Wusong da de laohu liuxue le.

(resultative, de)

Wusong beat DE tiger bleed PRT

'Wusong beat the tiger so that it bled.'

(2) a. Wusong huo zhuo le yi zhi laohu.

Wusong alive catch PRF one CL tiger

'Wusong caught a tiger alive.'

b. Wusong rere de he le yi wan jiu.

Wusong hot DE drink PRF one bowl wine

(depictive, de)

'Wusong drank a bowl of wine hot.'

This paper will make three claims. First, both depictives and resultatives are basegenerated as complement of a functional head, which is realized either by the word de or head-raising. Second, depictive constructions have an adjunct control structure, whereas resultative constructions have either a complement control or ECM-like structure. Finally, the surface position of $d e$ is derived by a PF operation which attaches de to the right of the leftmost verbal lexical head of the construction. Following Hornstein (2001: 103), no null operator for the syntactic structure of predication is assumed in this study.

In section 2, I will argue that the phrase that hosts secondary predicates is a functional category. In section 3, I will show that this functional phrase is merged as a complement of Vpri in resultative constructions and as an adjunct of the structure of the primary predication in depictive constructions. The surface positions of $d e$ and the secondary predicate in the V-V construction are discussed in section 4 . In section 5, the subject-orientation of resultatives, and the possible nonspecific reading of the subject of resultatives, in the V-V construction, are accounted for by the effect of head-raising. The paper is concluded in section 6 .

\section{The functional phrase in secondary predication}

The following two assumptions have been proposed by Hornstein \& Lightfoot (H\&L 1987) and Bowers (1993, 1997, 2000), among others. First, the phrase hosting a resultative or a depictive is a functional phrase. Second, a secondary predicate is the complement of the head of the functional phrase. In 2.1, I introduce the alternation between two constructions of secondary predication in Chinese, supporting these two assumptions. In 2.2, I claim that the functional phrase is vP.

\subsection{The projection of a functional phrase in secondary predication}

My first argument for the projection of a functional phrase is that secondary predicates such as depictives and resultatives in Chinese are represented in either the so-called deconstruction, where the functional word de occurs, or the $\mathrm{V}-\mathrm{V}$ construction, where Vpri is adjacent to the lexical head of the secondary predicate. In the following data, the secondary predicates in (3) and (4) are resultatives, and those in (5) and (6) are depictives. (3) and (5) are in the V-V construction, while (4) and (6) are in the de-construction.

If we classify these data according to the relevant position of the secondary predicates to Vpri, the resultatives in (3) and (4) are to the right of Vpri, whereas the depictives in (5) and (6) are to the left of Vpri. We will discuss this order issue in section 3.1. If we classify these data according to the orientation of the subject of the secondary predicates, we see that the secondary predicates in the a-sentences of (3) through (6) are subject-oriented, those in the 
b-sentences of (3) through (6) are object-oriented, and those in (3c) and (4c) have a subject independent of the argument structure of Vpri.

a. $\quad$ Akiu ku lei le.

Akiu cry tired PRF

'Akiu cried and as a result he felt tired.'

b. Akiu da shang le Fanjin.

Akiu beat wound PRF Fanjin

'Akiu beat Fanjin so that Fanjin was wounded.'

c. Akiu ku shi le shoujuan.

Akiu cry wet PRF handkerchief

'Akiu cried and as a result the handkerchief was wet.'

(4) a. Akiu wanr de wang le zuoye.

Akiu play DE forget PRF homework

'Akiu played so much that he forgot the homework.'

b. Akiu kua de Fanjin buhaoyisi le.

Akiu praise DE Fanjin embarrassed PRF

'Akiu praised Fanjin so that Fanjin felt embarrassed.'

c. Akiu ku de shoujuan ye shi le.

Akiu cry DE handkerchief also wet PRF

'Akiu cried and as a result the handkerchief was wet.'

(5) a. Jia Zheng zai nu da Baoyu. ${ }^{3}$

Jia Zheng PROG angry beat Baoyu

'Jia Zheng is beating Baoyu angry.'

b. Akiu huo zhuo le Nanbatian.

Akiu alive catch PRF Nanbatian

'Akiu caught Nanbatian alive.'

(6) a. Akiu hulihutu de mai le yi bao shipin.

Akiu confused DE buy PRF one package food

'Akiu bought a package of food confused.'

b. Akiu lala de chi le yi wan Dandan-mian.

Akiu spicy DE eat PRF one bowl Dandan-noodle

'Akiu ate a bowl of Dandan-noodle spicy.'

The alternation between the de-construction and the V-V construction of secondary predication is further shown by the unacceptability of (7) below. (7a) is neither a V-V construction nor a de-construction, whereas (7b) has both de and a V-V form. Both sentences are intended to encode a resultative meaning.
a. *Baoyu da na ge haizi haotaodaku.
Baoyu beat that CL child cry.loudly
b. *Baoyu da ku de na ge haizi.
Baoyu beat cry DE that CL child
Intended: 'Akiu beat that child so that the child cried.'

\footnotetext{
${ }^{3}$ Adjectives are not morphologically different from adverbs in Chinese. Thus the subject-oriented $n u$ 'angry' and hulihutu 'confused' in (6a) and (6b) respectively can also be manner expressions. Thus these sentences are ambiguous. In this paper, I discuss the argument-depictive reading of these sentences only. See Dechaine (1993) section 3.3.3.2 'Manner adverbs as (derived) event depictives' for a discussion of the semantic and syntactic relations between subject-oriented adjective depictives and the corresponding -ly adverbs in English.
} 
To capture this alternation, I assume that in Chinese, a functional phrase FP (to be specified in section 2.2) is projected in secondary predication, and $\mathrm{F}$ is realized by either de or a lexical head raised to $F$, as shown in (8a) and (8b), respectively. ${ }^{4}$
a. $\quad[\mathrm{FP}[\mathrm{F}, \mathrm{de}[\mathrm{XP}]]]$
b. $\quad\left[\mathrm{FP}\left[\mathrm{F}, \mathrm{X}_{\mathrm{i}}[\mathrm{XP}[\mathrm{v}, \mathrm{t}]],\right]\right]$

My second argument for FP is that within the same type of secondary predication, a resultative one or depictive one, the de construction and the $\mathrm{V}-\mathrm{V}$ construction share many syntactic properties, indicating that the two constructions are derived in similar ways. The projection of FP in both constructions and the similar way of integration of the FP into the structure of primary predication represent their syntactic similarities.

The two resultative constructions, the $\mathrm{V}-\mathrm{V}$ and the $d e$-construction, for instance, share at least the following six properties, calling for a unitary treatment. First, if Vpri is intransitive, and there is no other overt nominal to serve as a subject of the resultative, the null subject of the resultative in both the de and the $\mathrm{V}-\mathrm{V}$ constructions must be co-referential with the subject of Vpri. In the following b-sentences, the null subject of the resultative must be co-referential with Akiu rather than any other person.

a. Akiu shui de zhentou dou diao di-shang le.

Akiu sleep DE pillow even fall land-on PRF

'Akiu slept and as a result even the pillow fell on the ground.'

b. Akiu shui de yuntouzhuanxiang.

Akiu sleep DE dizzy

'Akiu slept and as a result he felt dizzy.'

(10) a. Akiu ku xing le Taotao.

Akiu cry awake PRF Taotao

'Akiu cried and as a result Taotao got awake.'

b. Akiu ku xing le.

Akiu cry awake PRF

'Akiu cried (in his dream) and as a result he got awake.'

Second, if the object of Vpri is absent, the verb is detransitivized, and the null subject of the secondary predicate must be co-referential with the subject of Vpri. In (11), the null subject of $l e i$ 'tired' is co-referential with Taotao, rather than the implicit patient of the Vpri.
a. Taotao zhui de hen lei.
Taotao chase DE very tired
'Taotao ${ }_{i}$ chased $\mathrm{X}_{\mathrm{j}}$ and as a result $\left\{\mathrm{he}_{\mathrm{i}} /{ }^{*} \mathrm{X}_{\mathrm{j}}\right\}$ got tired.'
b. Taotao ${ }_{i}$ zhui lei le.
Taotao chase tired PRF
'Taotao ${ }_{\mathrm{i}}$ chased $\mathrm{X}_{\mathrm{j}}$ and as a result $\left\{\mathrm{he}_{\mathrm{i}} /{ }^{*} \mathrm{X}_{\mathrm{j}}\right\}$ got tired.'

The above two points follow the general constraint on resultatives that their subject must have an overt antecedent (Carrier \& Randall 1992: 215, Rothstein 2000a). We will say more about this issue in section 3.4.2.

Third, in neither construction does the subject of the resultative predicate need to be the patient of the Vpri, which can be transitive in other contexts.

\footnotetext{
${ }^{4}$ Based on the alternation between the $d e$ and the V-V foms in resultative constructions, Sybesma (1999: 19) proposes that ExtP (Extent Phrase) is projected. The current study extends his ExtP to a more general functional phrase to cover the syntactic structures of all types of secondary predicate constructions.
} 
a. Akiu ti de qiuxie dou po le.

Akiu kick DE sneaker even broken PRF

'Akiu kicked so much that even the sneakers were broken.'

Akiu ti po le qiuxie.

Akiu kick broken PRF sneaker

'Akiu kicked so much that the sneakers were broken.'

(13) a. Akiu chi de ta fuqin dou mei qian le.

Akiu eat DE he father even not.have money PRF

'Akiu ate and as a result his father even had no money.'

b. Akiu chi qiong le ta fuqin.

Akiu eat poor PRF he father

'Akiu ate and as a result his father became poor.'

As noted by Cheng (1997), qiuxie 'sneaker' in (12) is not the patient of the verb $t i$ 'kick'. What Akiu kicked is a football, not his sneakers. Similarly, in (13), ta fuqin 'his father' is not the patient of the verb chi 'eat'. In both cases, the Vpris function like intransitive verbs. Data like (12) and (13) call for a unified approach to the two resultative constructions. Similar data in English, as shown in (14), are treated as constructions where Vpri is intransitive in Bowers (1993: 621).

(14) John drank himself/ his friends under the table.

Fourth, in both the V-V and the de-construction, the subject of Vpri can be a causer rather than an agent. In the following (15), the subject is both a causer and a patient; whereas in (16), the subject is simply a causer.

(15) a. zhe dun fan chi de Akiu hen bao.

This CL meal eat DE Akiu very full

'Akiu ate the meal and as a result he got very full.'

Lit: 'This meal ate Akiu very full.'

b. zhe shou ge chang hong le Akiu.

This CL song sing red PRF Akiu

'Akiu sang this song and as a result he became famous.'

Lit: 'This song sang Akiu red.'

(16) a. zhe ju hua xiao de Akiu liuchu-le yanlei.

this CL sentence laugh DE Akiu come.to-PRF tear

'This sentence got Akiu to laugh so much that he came to tears.'

Lit: 'This sentence laughed Akiu to tears.'

b. ta xiao si wo le.

he laugh die I PRF

'He made me laugh to the extent that I felt dead.'

Lit: 'He laughed me dead.'

In the current literature, a causer is base-generated at Spec of vP. It does not need to be an agent, and it does not need to interact with the structure below vP. In addition, verbs like chi 'eat' or chang 'sing' do not assign an agent theta role. An agent, if it occurs, gets its theta role from $v$ (Kratzer 1994). Huang (1994, 1997: 56) indeed assumes that the causer subject of the de-constructions like (16a) is merged at a higher verbal projection, although he does not apply his analysis to the $\mathrm{V}-\mathrm{V}$ construction. A unified approach to the two constructions proposed here correctly predicts that the two constructions can have the same type of $\mathrm{vP}$ projection in the structure of their primary predication. 
Fifth, if the subject of Vpri is a non-causer theme, no agentive adverbial such as guyi 'deliberately' is allowed. Compare (17), where the subject of the Vpri is a non-causer theme, with (18), where the subject of the Vpri is an agent:

a. tudou (*guyi) dun de hen lan.

potato deliberately stew DE very pappy

'The potatoes were stewed pappy (*deliberately).'

b. tudou (*guyi) dun lan le.

potato deliberately stew pappy PRF

'The potatoes were stewed pappy (*deliberately).'
a. Akiu guyi da de erzi haotaodaku.
Akiu deliberately beat DE son cry.loudly
'Deliberately, Akiu beat the son so that the son cried loudly.'

b. Akiu guyi da po le yi ge beizi.

Akiu deliberately hit broken PRF one CL cup

'Deliberately, Akiu hit a cup so that it was broken.'

According to Den Dikken \& Sybesma (1998), the ban of an agentive adverbial and the absence of the causative meaning in sentences like (17) indicate that vP, which hosts either an agent or causer, is not projected in the structure of the primary predication. Similar data can be found in Yorùbá (Dechaine 1993: 4.3.3), and Japanese (Nishiyama 1998: 189). As pointed out correctly by Nishiyama (1998: 199) "it is not that 'a transitive verb must have the external argument', but it is the other way around: the external argument must have a transitive verb." It is possible that the null subject of the secondary predicate is co-referential with the theme internal argument of the Vpri, which surfaces as the subject of the Vpri. The same constraint on the $\mathrm{V}-\mathrm{V}$ and the de-construction again calls for a unified treatment of the two constructions.

Sixth, the de-construction and the V-V construction show the same pattern of A'movement possibilities. Audrey Li (1999) presents quite a few arguments to show that topicalization in Chinese can be a movement operation. I adopt her conclusion as a background assumption. The following contrast between (19a) and (19b) shows that the internal argument of Vpri can be topicalized whereas the subject of a resultative which is not co-referential with any argument of the Vpri cannot be topicalized. The contrast between $(19 \mathrm{c})$ and (19d) shows that the internal argument of Vpri can be relativized, whereas the subject of a resultative which is not co-referential with any argument of the Vpri cannot be relativized.
a. na ben shu ${ }_{i}$ Akiu kan de $t_{i}$ dou lan le.
that CL book Akiu read DE even broken PRF
'That book, Akiu read and as a result it was broken.'
b. $\quad \underline{T a o t a o}_{i}$ Akiu ku de $t_{i}$ hen shangxin.
Taotao Akiu cry DE very sad
c. Akiu kan de $t_{i}$ dou po le de na ben $\operatorname{shu}_{i}$
Akiu read DE even broken PRF MOD that CL book
'the book that Akiu read and as a result became broken.'
Lit: 'the book that Akiu read broken'
d. $\quad *$ Akiu ku de $t_{i}$ hen shangxin de na ge ren ${ }_{i}$
Akiu cry DE very sad MOD that CL person
Lit: 'the person that Akiu cried sad'

The same contrasts are observed in the V-V construction: 

a. Na ge beizi $i_{i}$, Akiu da po le $t_{i}$. that CL cup Akiu hit broken PRF
'That cup, Akiu hit and as a result it was broken.'
b. $\quad \underline{A k i u}_{i}$, Taotao ku xing le $t_{i}$.
Akiu Taotao cry awake PRF
c. Akiu da po le $t_{i}$ de na ge beizi $i_{i}$
Akiu hit broken PRF MOD that CL cup
'the cup that Akiu hit and as a result became broken'
d. *Taotao $\mathrm{ku}$ xing le $\mathrm{t}_{\mathrm{i}}$ de na ge ren ${ }_{\mathrm{i}}$
Taotao cry awake PRF MOD that CL person

In fact, the subjects of the resultative predicates in (12), (13), (15), and (16) cannot undergo topicalization and relativization, either. They all pattern with the data where Vpri is intransitive. I will discuss this extraction issue in section 3.4.3.

Based on the above six similarities between the de-construction and the $\mathrm{V}-\mathrm{V}$ construction, I propose a unitary analysis of the two resultative constructions: a functional phrase FP is projected, and although the head of FP is realized differently, the integration of FP into the structure of the primary predication is the same.

The shared syntactic properties of the two constructions, on the other hand, are in concord with the assumption of the Distributive Morphology framework (Marantz 1997) that compound words are derived in the computational component rather than in the lexicon. My unitary syntactic approach is thus different from Yafei Li's (1990, 1998, 1999) non-unitary approach, which deals with the $\mathrm{V}-\mathrm{V}$ construction in the lexicon. For a discussion of the problems of the lexical approach, see Zou (1994) and Cheng (1997), among others.

\subsection{The nature of the assumed functional phrase}

The conclusion made in the last subsection supports H\&L and Bowers' assumption that there is a projection of a functional phrase in secondary predication. H\&L claim that the phrase is IP, whereas Bowers claims that it is PrP. I will, however, use $\mathrm{v}$ to represent the functional head, instead of H\&L's Infl and Bowers' Pr, for the following reasons.

H\&L (p. 28) assume that Infl, like all other heads, can be followed by any phrasal category as a complement, and that if Infl is [ \pm tense], the complement must be a VP; if Infl is empty, as in the non-primary predication constructions under discussion, the complement may be NP, PP, or AP, but not VP. First of all, however, this category contrast between primary and non-primary predicates is not universal (Dechaine 1993). In Chinese, a primary predicate can be a category other than VP, as shown by the AP predicate hen gao 'very high' in (21a), and a secondary predicate can be a VP, as shown by the VP resultative liuxu 'bleed' in (21b).
a. gongshui yijing (*shi) hen gao le.
flood already be very high PRT
'The flood has reached to a very high level.'
b. Wusong da de laohu liuxue le.
Wusong beat DE tiger bleed PRT
'Wusong beat the tiger so that it bled.'

Moreover, H\&L claim that the Infl in primary predicates has [ \pm tense] features, whereas the empty Infl in non-primary predicates does not. If so, one wonders why an IP headed by such an empty and featureless Infl is projected in the structure of non-primary predication at all. I do not claim that the head of the functional phrase in (8) is Infl, because the way the functional head is realized is not sensitive to a tense or finiteness contrast. 
I do not adopt Pr either, because it is not clear how to distinguish Pr from v, because we have no evidence that $\mathrm{v}$ and Pr can co-occur, and because what Pr can do can be covered by $\mathrm{v}$, which is motivated independently anyway.

One might wonder why there is no $d e-\mathrm{V}-\mathrm{V}$ alternation in a $\mathrm{vP}$ which encodes primary predication. The situation may be similar to the realization of the functional head related to a yes-no question in English. According to Chomsky (1995), if realizes this functional head. However, it never occurs in a root yes-no question.

I conclude this section by claiming that $\mathrm{vP}$ is projected in the structure of secondary predication. In Chinese, $\mathrm{v}$ is realized by either de or a head-raising in secondary predication.

One may assume that the choice between the de-merger and head-raising is determined in the Array (Chomsky 1998, 1999), in the sense that if de is present in the Array, the de-construction is derived; whereas if $d e$ is absent there, a head-raising occurs. Alternatively, one can assume that $d e$, like $d o$ of the $d o$-support in English, is a formative not present in the Array, and is used only when head-raising is impossible (cf. Chomsky 1957, Arnold 1995, Hornstein 2001: 184 on this analysis of the do-support). A typical case where head-raising is impossible is when the XP selected by v contains a degree word hen 'very', as in (22).
a. $\quad$ Lao Wang pao de hen lei.
Lao Wang run DE very tired 'Lao Wang run so that he got very tired.'
b. *Lao Wang pao lei hen.
c. *Lao Wang pao hen lei.

The choice of the de-construction rather than the V-V construction in (22) follows the constraint on head movement that no modifier can be stranded (Hoekstra 1988, see Sybesma 1999: 21).

\section{Adjunct vP vs. Complement vP}

Resultatives have been argued to be base-generated inside a complement of Vpri in English (Hoekstra 1988, Larson 1991a, Bowers 1993, 1997, 2000, among many others) and Japanese (Koizumi 1994). Subject-oriented depictives have been generally claimed to be basegenerated inside an adjunct of a verbal projection of the primary predication in both English and Japanese (H\&L 1987, Larson 1991a, Bowers 1993, 1997, 2000, Koizumi 1994). The base-position of object-oriented depictives, however, is under debate. Some including H\&L and Bowers, assume that object-oriented depictives are hosted by adjuncts of a verbal projection of the primary predication, whereas others, including Williams (1980), Culicover \& Wilkins (1984), Roberts (1988), Larson (1991a), and Koizumi (1994) claim that objectoriented depictives have the same structure as that of resultatives, i.e., they are hosted by a complement of Vpri.

In this section I show that in Chinese, the vP which hosts resultatives is a complement of Vpri, whereas the one that hosts depictives, regardless of whether the depictive is subjectoriented or object-oriented, is an adjunct of the structure of primary predication.

\subsection{The position with respect to Vpri}

In English, a VO language, secondary predicates are to the right of Vpri, as shown in (23). The resultative predicate flat is to the right of the Vpri watered in (23a), and the depictive predicate raw is to the right of the Vpri ate in (23b). In German as well as in Japanese, both 
OV languages, both types of predicates precede Vpri (abstracting away from V2). The German data in (24) show this point.
a. John watered the tulip flat.
(resultative)
b. John ate the fish raw.
(depictive)
a. Frank hat den Tisch sauber gewischt.
(resultative)
Frank has the table clean wiped
b. Frank hat das Fleisch roh geschnitten.
Frank has the meat raw cut
(depictive)

In Chinese, however, depictives precede, while resultatives follow, Vpri, as shown in the contrast between (2) and (1). In the de-construction, the former also precede de, while the latter also follow de. The surface positions of $d e$ will be argued to be decided at PF (section 4.2). Here I only consider the position of a secondary predicate with respect to Vpri.

The positions of secondary predicates are strict with respect to Vpri in Chinese, and may provide information about the integration of the $\mathrm{vP}$ argued for in section 2 into the structure of primary predication. In Chinese, complements of a verb occur to the right of the verb in unmarked cases, whereas adverbials of a verb occur to the left of the verb, as illustrated in (25a) and shown in (26). Similarly, as illustrated in (25b) and shown in the data in (27) as well as other Chinese data in this paper, resultatives occur to the right of Vpri while depictives occur to the left of Vpri.
a. adverbial $\mathrm{V}$
complement
b. depictive $\mathrm{V}$ resultative

b. Akiu \{zuotian/like\} $\quad x i$

Akiu yesterday/immediately wash PRF that CL shirt

'Akiu washed that shirt \{yesterday/immediately\}.'

b. *Akiu xi le na jian chenshan \{zuotian/like\}.

Akiu wash PRF that CL shirt yesterday/immediately

a. Akiu qihuhu de ti de men zhi yaohuang.

Akiu angry DE kick DE door continuously shake

'Akiu kicked the door shaky angry.'

b. *Akiu zhi yaohuang de ti de men qihuhu.

Akiu continuously shake DE kick DE door angry

These data show that depictives occur in a typical adverbial position, and resultatives occur in a typical complement position. The syntactic positions of depictives and resultatives with respect to Vpri in Chinese suggest that in the integration of a secondary predication into a primary one, depictives are hosted by a $\mathrm{vP}$ which is an adjunct of primary predicate, whereas resultatives are hosted by a vP which is a complement of Vpri.

\subsection{The co-occurrence restriction}

Resultatives do not co-occur with resultatives, while depictives can co-occur with depictives, as shown in (28). The restriction in English is discussed in Simpson (1983) and Rothstein (1985). The same contrast is observed in Chinese, as shown in (29).

(28) a. *John kicked the door open to pieces.

(resultative)

b. They ate the meat raw tender.

(depictive)

a. *Akiu da de Baoyu haotaodaku shou le shang.

(resultative)

Akiu hit DE Baoyu cry.loudly suffer PRF wound 
b. Akiu huoshengsheng de xinglixingqi de chi le na tiao yu. Akiu alive DE stinky DE eat PRF that CL fish

(depictive)

'Akiu ate that fish alive stinky.'

According to Winkler's (1997:7) semantic account, (28a) is unacceptable because resultatives are delimiting expressions and an event can only be delimited once in a sentence, whereas (28b) is acceptable because depictives are not delimiting expressions, and thus the restriction does not apply. The contrast can also be accounted for structurally. It is generally assumed that an element cannot have two or more complements of the same type. The two complements, direct and indirect object, of a ditransitive verb bear different thematic roles. However, an element can have two or more adjuncts of the same type. The above cooccurrence contrast between resultatives and depictives in English and Chinese provides another argument for the distinctions between complement and adjunct phrases which host secondary predicates.

\subsection{The hierarchy of depictives}

In this subsection we show that like adverbials, different types of depictives are structurally ordered in a hierarchy showing the properties of adverbials.

First, multiple depictives are ordered. When multiple depictives co-occur, we see mirror images of the orders in English and Chinese: In English, the order is object-oriented depictive - subject-oriented depictive (Carrier and Randall 1992), while in Chinese the order is just opposite; however, in both languages, object-oriented depictives are closer to Vpri than subject-oriented ones, as shown in the following:
a.
b. $\quad$ depictive $_{\text {sbj }}$ depictive $_{\text {obj }} \mathrm{V}$
$\mathrm{V}$ depictive $_{\mathrm{obj}}$ depictive $_{\text {sbj }}$
(English)
a. $\mathrm{John}_{\mathrm{i}}$ sketched the model $_{\mathrm{j}}$ nude $_{\mathrm{j}}\left[\mathrm{drunk}_{\mathrm{j}} \text { as a skunk }\right]_{\mathrm{i}}$.

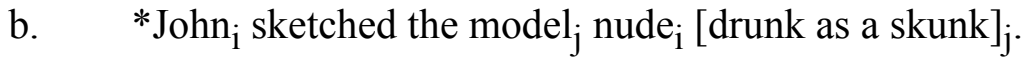
a. $\quad$ Akiu $_{i}$ yukuai $_{i}$ de rere $_{j}$ de he le [na wan cha $]_{j}$.
Akiu happy DE hot DE drink PRF that bowl tea
'Akiu drank that bowl of tea hot happy.'
b. ${ }^{*}$ Akiu $_{\mathrm{i}}$ rere $_{\mathrm{j}}$ de yukuai ${ }_{\mathrm{i}}$ de he le [na wan cha $]_{\mathrm{j}}$.
Akiu hot DE happy DE drink PRF that bowl tea

In (31), the depictive nude is closer to the Vpri sketched than the depictive drunk as a skunk. In the acceptable (31a), the subject of nude is co-referential with the model, which is the object of the Vpri, and the subject of drunk as a skunk is co-referential with John, which is the subject of the Vpri. (31b), with the opposite co-indexing, is unacceptable. Thus the objectoriented depictive is closer to the Vpri than the subject-oriented one. In (32), there are also two depictive predicates, rere 'hot' and yukuai 'happy'. In both sentences the subject of rere is co-referential with na wan cha 'that bowl of tea', which is the object of the Vpri he 'drink', and the subject of yukuai is co-referential with Akiu, which is the subject of he. Rere is closer to he 'drink' than yukuai in the acceptable (32a), whereas it is the other way around in the unacceptable (32b). Like (31), (32) also shows that the object-oriented depictive is closer to the Vpri than the subject-oriented one.

The pattern of the orders is similar to that of adverbials. In the following data ((34) is from Hornstein 2001: 116) the adjunct which has a dependency relation with the object of the matrix verb must be ordered closer to the matrix verb than the adjunct which has a dependency relation with the subject of the matrix verb. 
a. $\quad \mathrm{John}_{\mathrm{i}}$ arrested $\mathrm{Bill}_{\mathrm{j}}\left[\right.$ for $\mathrm{PRO}_{\mathrm{j}}$ driving his car too fast] [after $\mathrm{PRO}_{\mathrm{i}}$ leaving the party]

b. $\quad$ ?? $\mathrm{John}_{\mathrm{i}}$ arrested $\mathrm{Bill}_{\mathrm{j}}$ [after $\mathrm{PRO}_{\mathrm{i}}$ leaving the party] [for $\mathrm{PRO}_{\mathrm{j}}$ driving his car too fast]

a. $\mathrm{John}_{\mathrm{i}}$ bought Moby Dick $\mathrm{j}$ [for Mary to review $\mathrm{e}_{\mathrm{j}}$ ] $\left[\mathrm{PRO}_{\mathrm{i}}\right.$ to annoy Sam]

b. $\quad * J_{o h n}$ bought Moby Dick ${ }_{j}\left[\mathrm{PRO}_{\mathrm{i}}\right.$ to annoy Sam] [for Mary to review $\mathrm{e}_{\mathrm{j}}$ ]

There is no doubt that the non-finite clauses above are adverbials. Hornstein (2001: 97) claims that the adjunct which has a dependency relation with the object of the matrix verb is adjoined lower than the adjunct which has a dependency relation with the subject of the matrix verb. This difference in height indicates that the former has a closer structural relation to the matrix verb than the latter. In the linear order, the former is also closer to the matrix verb than the latter. The order restriction in (31) and (32) indicates that like the adverbials in (33)/(34), object-oriented depictives and subject-oriented depictives are ordered in a certain structural hierarchy. In H\&L (1987: 27), the functional phrase hosting a subject-oriented depictive is a VP-adjunct, whereas the functional phrase hosting an object-oriented depictive is a V'-adjunct. The Chinese data in (31) and (32) are compatible with this distinction.

Second, the interactions with adverbs show the structural order of different types of depictives. For instance, subject-oriented depictives can occur to the left of the adverb like 'immediately', while object-oriented depictives cannot, as shown in (35):
a.
Akiu (like)
gaoxing de (like)
chang le yi shou ge.
Akiu immediately glad DE immediately sing PRF one CL song
'Akiu sang a song glad (immediately).'
b. Akiu (like) rere de (*like) he le yi bei cha.
Akiu immediately hot DE immediately drink PRF one cup tea
'Akiu drank a cup of tea hot (immediately).'

This restriction shows that the vP hosting the object-oriented depictive may be ordered lower than both the adverb and the vP hosting the subject-oriented depictive on the adverbial hierarchy, and thus has a closer structural relation with the Vpri.

The similarity of the order-patterns of depictives to the order-patterns of adverbials, and the interactions with other adverbs suggest that the vP hosting depictives has properties of adverbials. This order fact supports our claim that vPs which host depictives have an adjunct status in their integration into the structure of primary predication.

A remaining issue is what syntactic operation enables co-reference between the null subject of a depictive and an argument of Vpri. In other words, what are the syntactic representations of the so-called subject-orientation or object-orientation of a depictive predication? Following H\&L, I assume that depictive constructions have a control-intoadjunct structure. In other words, the null subject of a depictive is a PRO, controlled by an argument of the relevant Vpri.

\subsection{The control and ECM properties of resultative constructions}

In this subsection, we show that resultative constructions are either in a complement-control or in an ECM structure. ${ }^{5}$ This in turn suggests that the phrase hosting resultatives is merged as a complement of Vpri.

\footnotetext{
${ }^{5}$ Huang (1992) claims that resultative constructions have a control structure. I do not discuss his argumentation here since he uses many data of the causative BA-construction and the passive-like BEI-construction, which makes the issue complicated and unclear.
} 
I argue for Bowers' $(1993,1997,2000)$ claim that the resultative construction where the Vpri thematically selects the unique overt affected argument has a control structure whereas the construction where the Vpri does not do so is an ECM-like structure. I call the former construction TRC (Transitive Resultative Construction) and the latter IRC (Intransitive Resultative Construction). In (36a), the Vpri wipe selects the affected argument the table, thus (36a) is a TRC. In (36b), the Vpri ran does not select the affected argument their Nikes, thus (36b) is an IRC. The parallel Chinese resultative examples are (37) and (38), respectively.
a. John wiped the table clean.
(TRC)
b. The joggers ran their Nikes threadbare.
a. Akiu da si le laohu.
$(=1 \mathrm{a})$
$(\mathrm{TRC}, \mathrm{V}-\mathrm{V})$
Akiu beat die PRF tiger
'Akiu beat the tiger so that it died.'
b. Akiu da de laohu liuxue le.
'Akiu beat the tiger so that it bled.'
$(=1 \mathrm{~b}) \quad(\mathrm{TRC}, \mathrm{de})$
a. Akiu ku shi le shoujuan.
(IRC, V-V)
Akiu cry wet PRF handkerchief
'Akiu cried and as a result the handkerchief was wet.'
b. Akiu ku de shoujuan ye shi le.
(IRC, de)
Akiu cry DE handkerchief also wet PRF
'Akiu cried and as a result the handkerchief was wet.'

(38)

It is possible that the subject of a resultative predicate is a null form, as in (39).
a. $\quad$ Akiu ku lei le.
$(=3 \mathrm{a})$
Akiu cry tired PRF
'Akiu cried and as a result he felt tired.'
b. Akiu wanr de wang le zuoye. (=4a)
Akiu play DE forget PRF homework
'Akiu played so much that he forgot the homework.'

Similar data have been presented in (9b), (10b), and (11). In these data, the null subject of the resultative predicate is co-referential with the subject of Vpri, rather than the implicit patient of Vpri, if there is one. This type of data should be given the same treatment as that of other IRCs.

\subsubsection{Against the unitary approaches to TRC and IRC}

In the current literature, the approach represented by Hoekstra (1988) and Sybesma (1999) treats the affected argument in both TRC and IRC as subject of the resultative predicate. In contrast, the approach suggested by Rothstein (2000a: 259) tends to treat the affected argument in both TRC and IRC as an object of the Vpri. The following discussion will argue against these two unitary approaches.

In Korean, the affected argument has accusative case in TRC, whereas a nominative case in IRC (Kim \& Maling 1997: 191). In English, the differences between TRC and IRC are noted by Wilder (1991, 1994), Carrier \& Randall (1992), and Rothstein (1992), among others. They found that the two constructions contrast in selectional restrictions, middle formation, nominalization, subjacency violation, and semantic entailment. They claim that the contrasts indicate that the affected argument is the object of the Vpri in TRC, whereas it is the subject of the resultative predicate in IRC. In Chinese, the same claim is argued for by Li (1998: 287). I provide two more arguments for this non-unitary approach: a contrast in the adjacency 
between the Vpri and the affected argument, and a contrast in extraction of the affected argument. Chinese:

A focussed object can be preposed to either the left or the right of the subject in
(lian mingzi $i_{i}$ ) Akiu (lian mingzi $i_{i}$ ) dou wang-le $t_{i}$
even name Akiu even name also forget-PRF
'Akiu forgot even the name.'

In a TRC, the object of the resultative predicate can only be preposed to the right of the affected argument, as shown in (41a). In an IRC, however, the object of the resultative predicate can be preposed to either the left or the right of the affected argument, as shown in (41b):
a.
Daiyu kua de (*lian mingzi $\left.i_{i}\right)$ Baoyu (lian mingzi $\left.i_{i}\right)$ dou wang-le $t_{i}$. (TRC)
Daiyu praise DE even name Baoyu even name also forget-PRF
'Daiyu praised Baoyu and as a result Baoyu forgot even the name.'
b. Daiyu ku de (lian mingzi $i_{i}$ ) Baoyu (lian mingzi $i_{i}$ ) dou wang-le $t_{i}$.
Daiyu cry DE even name Baoyu even name also forget-PRF
'Daiyu cried and as a result Baoyu forgot even the name.'

The contrast is expected if Baoyu is the object of the Vpri in (41a), but the subject of the resultative predicate in (41b), because the pre-Baoyu nominal lian mingzi 'even name' is in the permitted clause-initial position in (41b), but illegitimately intervenes between the Vpri and its object in (41a), making the sentence unacceptable.

Another relevant contrast is the extraction contrast between TRC and IRC presented in (19) and (20). Specifically, extraction of an affected argument is possible in TRC, but not in IRC. We will discuss this contrast in section 3.4.3.

The above two contrasts between TRC and IRC strongly suggest that the two constructions have different structures. Following Rothstein (1992) and Levin \& Rappaport Hovav (1995), among others, I will analyze the affected argument as a subject of the resultative predicate in IRC and as an object of the Vpri in TRC.

\subsubsection{A control analysis of TRC}

Chinese TRCs have both object-control and subject-control structures. For an object-control structure, consider (42):

(42) a. Akiu kan de zhe ben shu dou lan le.

Akiu read DE this CL book even broken PRF

'Akiu read this book and as a result the book even got broken.'

b. *Akiu kan de zhe ben shu dou bunaifan le.

Akiu read DE this CL book even impatient PRF

In (42), the affected argument zhe ben shu 'this CL book' is thematically selected by and is an object of the Vpri kan 'read'. The null subject of the resultative dou lan le 'even broken PRF' is co-referential with the object. This co-reference relation obeys the Minimal Distance Principle (MDP, Rosenbaum 1970) on control, which roughly states that a PRO selects as its controller the nearest c-commanding nominal. The nearest c-commanding overt nominal to the resultative predicate must be the controller of the PRO subject of the predicate. In (42a) the nominal is zhe ben shu 'this book' rather than Akiu. In (42b), however, MDP requires zhe ben shu 'this book' to be the controller of the PRO subject, but semantically this overt 
nominal cannot be predicated of by the resultative predicate bunaifan 'impatient'. Consequently the predication fails.

One argument for the object-control construction of (42a) is that it obeys Bach's generalization (Bach 1979, Larson 1991b), which states that detransitivization is available with subject-control verbs but proscribed with object-control verbs.
a. John promised (Mary) to leave.
(subject-control)
b. John \{persuaded/forced $\}$ (Mary) to leave.
(object-control)

As in (43b), if we remove the object from (42a), the sentence becomes unacceptable:

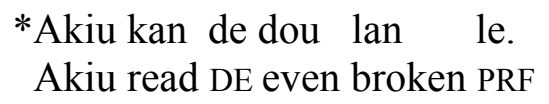

Bach's generalization captures the constraint that in obligatory control, PRO must have an overt antecedent (H\&L 1987: 36). Returning to data like (11), repeated here as (45), we now can see why the subject of the resultative here cannot be co-referential with the implicit patient of the Vpri.
a. Taotao ${ }_{i}$ zhui de hen lei.
Taotao chase DE very tired
'Taotao ${ }_{\mathrm{i}}$ chased $\mathrm{X}_{\mathrm{j}}$ and as a result $\left\{\mathrm{he}_{\mathrm{i}} /{ }^{*} \mathrm{X}_{\mathrm{j}}\right\}$ got tired.'
b. Taotao zhui lei le.
Taotao chase tired PRF
'Taotao ${ }_{\mathrm{i}}$ chased $\mathrm{X}_{\mathrm{j}}$ and as a result $\left\{\mathrm{he}_{\mathrm{i}} /{ }^{*} \mathrm{X}_{\mathrm{j}}\right\}$ got tired.'

In this respect, an obligatorily controlled PRO is like reciprocals and reflexives ((46a,b), Chomsky 1986), and unlike pronouns (46c) and a non-obligatorily controlled PRO (46d), which do not require an overt antecedent (H\&L: 36, Hornstein 2001):

(46) a. They $y_{\mathrm{i}}$ decided to hit $\{\text { each other/themselves }\}_{\mathrm{i}}$.

b. $\quad *$ Damaging testimony was given about $\{$ each other/themselves .

c. The boat was sunk in order [that he could collect the insurance].

d. The boat was sunk [PRO to collect the insurance].

We have shown that data like (42) have object-control structures. The following data (adapted from Y. Li 1999: 448) exhibit properties of subject-control structures, i.e., the PRO subject of the resultative predicate is controlled by the nearest subject Daiyu.

a. (Akiu zhidao) Daiyu deng de Baoyu PRO $_{\text {Daiyu }}$ zuolibu'an.

Akiu know Daiyu wait DE Baoyu restless

'(A. knew that) D. waited for B. and as a result D. became restless.'

b. (Akiu tingshuo) Daiyu xiang de Baoyu PRO $_{\text {Daiyu }}$ shuibuzhaojiao.

Akiu hear Daiyu miss DE Baoyu unable.sleep

'(A. heard that) D. missed B. so much that D. could not sleep.'

Like other resultative constructions, data like (47) describe a resultative state which is caused by the action denoted by the primary predication. According to Larson (1991b: 115, adopted in Bowers 2000: 321) and Hornstein (2001) the object of subject-control verbs does not c-command the PRO, since it is hosted by an adjunct of the verb. Thus MDP is not violated in the controlling of the PRO by John in John promised Mary to leave and Akiu in 
(47). ${ }^{6}$ Hornstein (2001: 64 fn 19) suggests that the object of promise is the object of a null preposition corresponding to the to in the nominal form in (48a), as shown in (48b):
a. John's promise to Mary to leave
b. John promised [PP P Mary] [PRO to leave]

As in the object-control cases, MDP is obeyed in (47). The PRO is controlled by the nearest c-commanding nominal Daiyu, rather than Akiu, which is not a nearest c-commanding nominal.

In addition, Bach's Generalization is also observed. (49) shows that as in (43a), detransitivization of the Vpri in (47a) does not change the control pattern.

Daiyu $_{\mathrm{i}}$ deng de zuolibu'an.

Daiyu wait DE restless

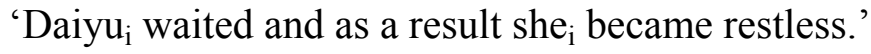

The following data show that the subject-control property of deng 'wait' and xiang 'miss' is kept in the V-V construction:
a. $\quad$ Akiu $_{\mathrm{i}}$ deng $\mathrm{ji}$
le Daiyu $_{\mathrm{j}} \mathrm{PRO}_{\mathrm{i}}$ (pro da dianhua wen zenme-huishi).
Akiu wait impatient PRF Daiyu
make call ask what-thing
'Akiu ${ }_{i}$ waited for Daiyu $u_{j}$ so much that he ${ }_{i}$ became impatient
(and then he made a phone call asking what happened)'
b. $\quad$ Akiu $_{\mathrm{i}}$ xiang feng le Daiyu $\mathrm{PRO}_{\mathrm{i}}$.
Akiu miss mad PRF Daiyu

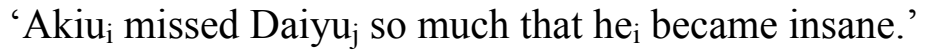

Subject-control verbs are less common than object-control verbs. ${ }^{7}$ If the Vpris in (47) are replaced by other transitive verbs such as kua 'praise', ma 'scold', or piping 'criticize', the PRO subject of the resultative predicate will be controlled by the object Baoyu rather than the subject Daiyu (I will discuss the issue of subject-orientation of the V-V TRC in section 5.1).

\subsubsection{A ECM analysis of IRC}

Bowers (1993: 622, 1997: 45, 2000: 325) argues that in the English IRCs, the subject of the secondary predicate raises to the higher clause, as shown in (51):
a. The joggers ran their Nikes ${ }_{i}\left[\mathrm{PRP}_{\mathrm{i}} \mathrm{t}_{\mathrm{i}}\right.$ threadbare].
b. John ate himself ${ }_{\text {[PRP }} t_{i}$ sick].

Based on the arguments presented in Lasnik \& Saito (1991), Chomsky (1995) claims that an ECM structure is derived by movement of the embedded subject to a specifier position in the higher clause. The essence of Bowers' ECM analysis of IRCs is that the subject of the resultative predicate has a theta relation locally, whereas it has a Case relation with the primary predication, and thus behaves like an object of Vpri.

\footnotetext{
${ }^{6}$ Larson (1991b) claims that subject-control verbs are ditransitive verbs. However, it has been pointed out to me that dative shift verbs other than promise still take object-control. For example, tell permits dative shift, as in $I$ told Mary the answer, but tell is nevertheless an object-control verb, as in John told Mary PRO to kill herself/*himself. Thus in my present work I do not link the subject-control property of verbs such as promise to the dative shift property. In addition, Chinese verbs like deng 'wait' and xiang 'miss' have no dative shift property anyway:
(i) a. *Akiu deng le Baoyu yi feng xin.
Akiu wait PRF Baoyu one CL letter
b. *Akiu xiang le Baoyu yi feng xin.
Akiu miss PRF Baoyu one CL letter
${ }^{7}$ Acquisition evidence shows that subject-control verbs are marked in English (see Hornstein 2001: 35). 
Bowers' analysis can be supported by the fact that the affected argument in IRC shows object properties. Rothstein (2000a: 256) uses the following evidence to show that the affected argument in IRC has properties of a direct object. As is well known, accomplishments can have an atelic reading if their direct object is a bare plural or a mass noun. She notes that the event denoted by IRC can be atelic if the affected argument is a bare plural or a mass noun. The data in (52) have atelic counterparts in (53):

(52) a. John sang the baby asleep.

b. The audience laughed the clown off the stage.

a. John sang babies asleep for hours last night.

b. The audience was very cruel and laughed performers off the stage as fast as they could come on.

Since objects in Chinese do not raise overtly for Case reasons, I assume that if there is a Case relation between a verb and the subject of its complement clause (an ECM structure), the relevant Case checking is accomplished either by covert raising of the embedded subject or without any movement (Chomsky's $(1998,1999)$ Agree). I have three arguments for the ECM structure of IRC in Chinese. First, the affected argument in IRC has properties of a typical object. This is shown by the fact that such an argument can occur to the left of the Vpri in the BA construction, as in (54a). The affected argument in this sense is similar to an affected object of a transitive verb, as in (54b). Generally, nominals construed with an intransitive verb cannot occur in the BA construction, as shown in (55), where shi 'wet' and $q u$ 'go' are intransitive verbs: ${ }^{8}$
a. Akiu ba shoujuan ku de quan shi-le.
Akiu BA handkerchief cry DE complete wet-PRF
'Akiu cried and as a result the handkerchief was completely wet.'
b. Akiu ba mianbao chi-le.
Akiu BA bread eat-PRF
'Akiu ate the bread.'
a. *Akiu ba shoujuan shi-le.
Akiu BA handkerchief wet-PRF
b. *Akiu ba Xizang qu-le.
Akiu BA Tibet go-PRF

Second, unlike in the $d e$-TRC, the affected argument in the de-IRC can be nonspecific, and the available nonspecific reading is found in objects rather than subjects in Chinese (I will discuss the specificity issue of the $\mathrm{V}-\mathrm{V}$ construction in section 5.2). The subject of a primary predicate, regardless of whether the predicate is individual-level or stage-level, cannot be nonspecific in Chinese generally (Li \& Thompson 1981, Tsai 2001, among others), as shown in (56a). The same constraint is observed in the PRO subject of the resultative predicate in the de-TRC, as shown in (56b).

\footnotetext{
${ }^{8}$ It has been mentioned to me that (ib) is not acceptable (contra Huang 1992: 111).

(i) a. Akiu ba Baoyu ku de hen gan'ga.

Akiu BA Baoyu cry DE very embarrassed

'Akiu cried and as a result Baoyu got very embarrassed.'

b. ??Akiu ba Baoyu ku de hen shangxin.

Akiu BA Baoyu cry DE very sad

'Akiu cried and as a result Baoyu got sad.'

I have no account for the unnaturalness of (ib), compared to the grammatical (ia), as well as (54a).
} 


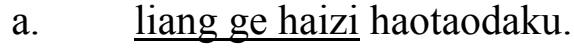

two CL child cry.loudly

'The two children cried loudly.'

Not: 'There are two children, who cried loudly.'

b. Akiu da de liang ge haizi ${ }_{i}$ PRO $_{\mathrm{i}}$ haotaodaku.

Akiu beat DE two CL child cry.loudly

'Akiu beat the two children and as a result they cried loudly.'

Not: 'There are two children, whom Akiu beat and as a result they cried loudly.'

The affected argument in the $d e$-IRC, however, can be nonspecific, as shown below. Thus the argument has a property of objects rather than subjects in this respect.

(57) a. Akiu xiao de liang hang yanlei gua zai le lian-shang.

Akiu laugh DE two line tear hang at PRF face-on

'Akiu laughed and as a result two lines of tears appeared on his face.'

b. Akiu han de xuduo ren fenfen likai le hui-chang.

Akiu shout DE many people one.after.another leave PRF meeting-hall

'Akiu shouted and as a result many people left the meeting hall.'

Third, unlike in an TRC, extraction out of an IRC is difficult, and the contrast patterns with the contrast between a control and an ECM structure in general. In the de-construction data in (58) and the V-V construction data in (59), topicalization and relativization of the internal argument of Vpri of TRC are possible; however, topicalization and relativization of the affected argument in IRC are not allowed.

(58) a. na shuang xie ${ }_{i}$ Akiu chuan de $t_{i}$ dou po le. (de-TRC) (similar to 19) that pair shoe Akiu wear DE even broken PRF

'That pair of shoes, Akiu wore and as a result they were broken.'

b. *na tiao shoujuan ${ }_{i}$ Akiu ku de $t_{i}$ hen shi. (de-IRC) that CL handkerchief Akiu cry DE very wet

c. Akiu chuan de $t_{i}$ dou po le de na shuang xie ${ }_{i}$ (de-TRC)

Akiu wear DE even broken PRF MOD that pair shoe

'that pair of shoes that Akiu wore and as a result became broken.'

d. *Akiu $\mathrm{ku}$ DE $\mathrm{t}_{\mathrm{i}}$ hen shi de na tiao shoujuan (de-IRC)

Akiu cry DE very wet MOD that CL handkerchief

(59) a. Na shuang $x \mathrm{x}_{\mathrm{i}}$, Akiu chuan po le $\mathrm{t}_{\mathrm{i}}$ (V-V TRC) (similar to 20) that pair shoe Akiu wear broken PRF

'That pair of shoes, Akiu wore and as a result they were broken.'

b. *na tiao shoujuan, ${ }_{i}$, Akiu ku shi le $\mathrm{t}_{\mathrm{i}}$. (V-V IRC) that CL handkerchief Akiu cry wet PRF

c. Akiu chuan po le $t_{i}$ de na shuang xie (V-V TRC)

Akiu wear broken PRF MOD that pair shoe

'that pair of shoes that Akiu wore and as a result became broken'

d. *Akiu ku shi le $t_{i}$ de na tiao shoujuan (V-V IRC)

Akiu cry wet PRF MOD that CL handkerchief

In English, no such contrast is seen in a short-distance extraction:

(60) a. The joggers ran their Nikes threadbare.

b. Those Nikes, the joggers ran threadbare. (topicalization)

c. the Nikes that the joggers ran threadbare (relativization)

(61) a. John drank those people under the table. 
b. Those people, John drank under the table.

(topicalization)

c. the people whom John drank under the table

(relativization)

However, the contrast is revealed in a long-distance extraction (Rothstein 1992, 2000b):

(62) a. Which table did you ask whether John wiped clean?

b. ??Which baby did you ask whether John sang asleep?

In (62a), the wh-nominal which table in the TRC moves out of the weak wh-island (the complement whether-clause), whereas in (62b), it is hard for the wh-nominal which baby in the IRC to undergo the similar movement.

The data in (63) show that in tough-constructions, extraction of an embedded object out of a control structure is easier than extraction of an embedded object out of an ECM structure (Chung 2001).
a. ?Which book was John hard for us to persuade to read?
b. $\quad *$ Which book was John hard for us to expect to read?

The extraction data above indicate that it is easier to extract a nominal from a control structure than from an ECM structure. The extraction contrast introduced above between TRC and IRC may reflect the contrast between a control structure and ECM structure in general.

The two analyses, control and ECM, presented in Bowers (1993, 1997, 2000) and adopted in this paper, can capture the properties of the TRC and IRC. Specifically, in TRC the patient argument is the controller of the PRO subject of the resultative predicate. In IRC, however, there is no PRO, and the subject of the resultative predicate has a Case relation with the Vpri. The Case relation is similar to that between a transitive verb and its object. Thus the subject of the resultative in IRCs shows some, but not all, properties of objects. In Chinese, on the one hand, the subject of a resultative predicate in IRC can occur in the BA construction and can be nonspecific, as shown in (54a) and (57), respectively, exhibiting object properties. On the other hand, as shown in (41b), the subject of the resultative predicate can be preceded by some element in IRC, whereas a typical object cannot. This can be explained if the subject does not move overtly to the object position of the Vpri.

I conclude this subsection by claiming that in TRC, the subject of the resultative is a PRO, which can be viewed as a trace of a theta-to-theta movement (Hornstein 1999), whereas in IRC, the subject of the resultative is a regular overt nominal, not a PRO. However, the properties of both a control structure and an ECM-like structure indicate that the vP which hosts resultatives is a complement of Vpri, in both types of resultative constructions.

Based on the above four aspects, i.e., the position with respect to Vpri, the cooccurrence restriction, the hierarchy of depictives, and the control/ECM properties of resultative constructions, we conclude that the $\mathrm{vP}$ hosting secondary predicates are integrated into the structure of primary predication in two ways: as a complement of Vpri, or as an adjunct. The former case is found in resultative constructions, and the latter case is found in depictive constructions.

\subsection{The locality of integration of a vP into the structure of primary predication}

In both Chinese and English, the subject of a secondary predicate cannot be co-referential with the object of a preposition (Williams 1980: 204). For instance, the subject of the resultative predicate full is co-referential with the object of the Vpri, wagon, in (64a); however, the subject of full cannot be co-referential with wagon, which is the object of the 
preposition into, in (64b). Similarly, the subject of the depictive predicate green cannot be coreferential with hay, which is the object of the preposition with, in (64d).

(64) a. John loaded the wagon full [with hay].

b. *John loaded the hay [into the wagon] full.

c. John loaded the hay [into the wagon] green.

d. *John loaded the wagon [with hay] green.

The same constraint is found in Chinese. In the reading of (65a), it is Akiu rather than Baoyu who was excited. In other words, the subject of the depictive predicate xingfen 'excited' is co-referential with the subject of Vpri, Akiu, rather than Baoyu, which is the object of the preposition $d u i$ 'to'. Similarly, the subject of the depictive predicate rere 'hot' is co-referential with the object of Vpri, yi wan tang 'one bowl of soup', rather than chufang 'kitchen', which is the object of the preposition zai 'at', in (65b). In (65c), the subject of the depictive predicate ruanruan 'soft' cannot be co-referential with na tiao maojin 'that towel', which is the object of the preposition wei 'for'. It can only be co-referential with the subject of Vpri, i.e., Akiu; however, semantically, a person cannot be predicated of by ruanruan, and thus the sentence is unacceptable. In the V-V construction $(65 \mathrm{~d})$, the subject of the depictive predicate $n u$ 'angry' is co-referential with Akiu, which is the subject of the Vpri ma 'scold', rather than Baoyu, which is the object of the preposition miandui 'toward'. The parralel resultative data are presented in (66). The subject of the resultative predicate mei xinsi kan shu 'have no mood to read books' cannot be co-referential with Baoyu, which is the object of the preposition miandui 'towards', in (66b). In the V-V construction (66c), the subject of the resultative predicate $k u$ 'cry' is co-referential with Daiyu, which is the object of the Vpri da 'beat', rather than Baoyu, which is the object of the preposition miandui 'toward'.

(65) a. Akiu [dui Baoyu] xingfen de shuo le xuduo hua.

Akiu to Baoyu excited DE speak PRF many words

'Akiu said many words to Baoyu excited.'

b. Akiu [zai chufang li] rere de he le yi wan tang.

Akiu at kitchen in hot DE drink PRF one bowl soup

'Akiu drank a bowl of soup in the kitchen hot.'

c. *Akiu [wei na tiao maojin] ruanruan de zou-jin le yu-shi.

Akiu for that CL towel soft DE walk-enter PRF bath-room

d. Akiu [miandui Baoyu] nu ma Daiyu.

Akiu toward Baoyu angry scold Daiyu

'Akiu scolded Daiyu angry in front of Baoyu.'

(66) a. Akiu ku de mei xinsi kan shu le.

Akiu cry DE not.have mood read book PRT

'Akiu cried so that he had no mood to read books.'

b. Akiu [miandui Baoyu] ku de mei xinsi kan shu le.

Akiu towards Baoyu cry DE not.have mood read book PRT

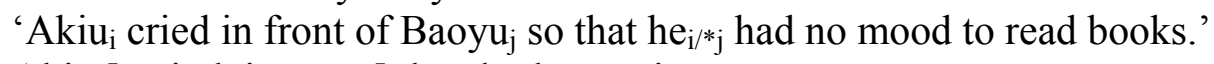

c. Akiu [maindui Baoyu] da ku le Daiyu.

Akiu toward Baoyu beat cry PRF Daiyu

'Akiu beat Daiyu in front of Baoyu so that Daiyu cried.'

None of the subject-oriented depictive in (67a), the object-oriented depictive in (67b), and the resultative in $(67 \mathrm{c})$ can be co-referential with the possessor in the constructions.

a. Akiu de erzi shangxin de jiang le yi ge gushi.

Akiu MOD son sad DE tell PRF one CL story

'Akiu's son told a story sad.'

(It is not Akiu who was sad.) 
b. Akiu huo zhuo le na zhi laohu de zaizi.

Akiu alive catch PRF that CL tiger MOD baby

'Akiu caught the baby of that tiger alive. (It is not the parent who was alive.)

c. Akiu da de na zhi laohu de zaizi liuxue le.

Akiu beat DE that CL tiger MOD baby bleed PRT

'Akiu beat the baby of that tiger so that it bled.' (It is not the parent who bled.)

Williams accounts for the English data like (64) by the C-command condition on his co-indexing operation of predication in general. The above data show that if the subject of a secondary predication is co-referential with a nominal of a primary predication, the nominal must be an argument of Vpri rather than any other nominal. The constraint indicates that the integration of a secondary predication into a primary one must be syntactically local. This locality constraint should follow the general principles of syntactic computations. In resultative constructions, we have argued that they have control (for TRCs) or ECM-like (for IRCs) structures. In the control structure, the general C-Command condition prohibits a PRO from being controlled by the object of a preposition, thus the impossibility for the subject of a resultative predicate to be co-referential with the object of a preposition is accounted for. Similarly, the general C-Command condition also prohibits a PRO from being controlled by a nominal internal to an argument nominal, thus the impossibility for the subject of a resultative predicate to be co-referential with the possessor of a nominal is also accounted for. In the ECM-like structure, the embedded subject has a Case relation with the verb, rather than a preposition or other nominal in the upper clause. Thus the impossibility for the subject of a resultative predicate to be co-referential with the object of a preposition or a possessor is also captured.

As for depictive constructions, we have assumed that they have control-to-adjunct structures. I then simply assume that whatever principle which rules out the impossible control in (68), rules out the impossible control in the depictive constructions in (65) and $(67){ }^{9}$

(68) a. John arrested Bill $l_{\mathrm{i}}$ behind $\operatorname{Tim}_{\mathrm{j}}\left[\right.$ for $\mathrm{PRO}_{\mathrm{i} /{ }_{\mathrm{j}}}$ driving his car too fast]

b. John arrested Bill' ${ }_{\mathrm{j}} \mathrm{s}$ brother ${ }_{\mathrm{i}}\left[\right.$ for $\mathrm{PRO}_{\mathrm{i} / * \mathrm{j}}$ driving his car too fast]

Depictive constructions thus differ from parasitic gap (pg) constructions. On the one hand, pgs, by definition, require real gaps to "license" them, whereas the null subject of depictives does not. In other words, the controller of the PRO subject of a depictive does not need to undergo any movement. On the other hand, pgs can be related to a real gap which is

\footnotetext{
${ }^{9}$ One might assume that the null subject of a depictive predicate is the trace of a sideward theta-to-theta movement from an adjunct vP to an argument position of the primary predication, adopting Nunes \& Uriagereka (2000) and Hornstein (2001). In the depictive constructions in (65), if the null subject of the depictive predicate were co-referential with the object of the preposition, the assumed sideward movement would land at a position internal to a PP. Nunes and Uriagereka (2000: 38) claim that "sideward movement from a derivational workspace $\mathrm{W}_{1}$ to a derivational workspace $\mathrm{W}_{2}$ yields licit result just in case $\mathrm{W}_{1}$ will be embedded in $\mathrm{W}_{2}$ at some derivational step." In the licit derivations of depictive constructions, the sideward movement of a nominal lands at an argument position of the verbal projection of the primary predication, and the vP where the sideward movement starts is finally embedded to the verbal projection. In data like (65), the adjunct PP itself is an independent derivational workspace. If a sideward movement lands at a position internal to the PP, obviously, the vP where the sideward movement starts is never embedded to the PP. Thus such a derivation is not licit. Consequently, co-reference of the subject of a depictive predicate with an object of a preposition is impossible.

However, this embedded-to-embedding-account has both empirical and theoretical problems. Empirically, it cannot cover the parasitic data like (69), where an assumed sideward movement lands internal to a PP. Theoretically, this embedded-to-embedding-account is not a local consideration. To judge the possibility of a certain step derivation one needs to check the future steps of the derivation.
} 
an object of a preposition, as shown in (69) (Hornstein 2001: 114) and (70a) (Hornstein 2001: $79,123)$, whereas the null subject of a depictive cannot co-referential with an object of a preposition, as shown above.

(69) a. Who did you show the book [to t] before Fred introduced pg.

b. Who did you talk to me [about $\mathrm{t}$ ] right after Fred introduced pg.

(70) a. This is a topic that you should think about $t$ before talking about pg.

b. $\quad *$ This is a topic about which you should think $\mathrm{t}$ before talking $\mathrm{pg}$.

In this section, I have studied the syntactic properties of depictive and resultative predicates, arguing that the former are hosted by an adjunct $\mathrm{vP}$, while the latter are hosted by a complement vP. The ways in which they are integrated into the structure of primary predication follow the general principles governing computations of complements and adjuncts.

\section{The surface position of the element realizing of $v$ in secondary predication}

In this section we discuss the surface position of an overt element at v, i.e., de or the secondary predicate in the $\mathrm{V}-\mathrm{V}$ construction. I will make the following claims. The surface position of $d e$ is decided at PF. In the $\mathrm{V}-\mathrm{V}$ construction, the lexical head of a depictive predicate first raises to $\mathrm{v}(8 \mathrm{~b})$ and then left-adjoins to Vpri at PF, while the lexical head of a resultative predicate undergoes successive head raising in syntax.

\subsection{The V-V Constructions}

In the depictive V-V construction, the depictive predicate is left-adjacent to Vpri, while in the resultative $\mathrm{V}-\mathrm{V}$ construction, the resultative predicate is right-adjacent to Vpri. This is shown in the possible positions of adverbs such as like 'immediately' and yijing 'already' in (71):
a. Akiu (like)
sheng $(*$ like)
chi le na tiao yu.
Akiu immediately raw immediately eat PRF that CL fish
'Akiu (immediately) ate that fish raw.'
b. Akiu (yijing) da (*yijing) ku le Baoyu.
Akiu already beat already cry PRF Baoyu
'Akiu (already) beat Baoyu so that Baoyu cried.'

In (71a), the depictive predicate sheng 'raw' is immediately left-adjacent to the Vpri chi 'eat'. In (71b), the resultative predicate verb $k u$ 'cry' is immediately right-adjacent to the Vpri $d a$ 'beat'. In neither case can the adverb occur between the Vpri and the secondary predicate.

Although both types of secondary predicates are adjacent to Vpri, the depictive sequence of [V-Vpri-Asp] is opaque to syntactic operations, while the resultative sequence of [Vpri-V-Asp] is not. This can be shown by the so-called A-not-A formation, a yes-no question formation in Chinese. In this operation, a yes-no [Q] feature is integrated into a verb, deriving a form where the verb is reduplicated, and an appropriate form of the negation word occurs between the two copies of the verb, as shown in (72b).

a. Akiu chi le na tiao yu.

Akiu eat PRF that CL fish

'Akiu ate that fish.' 
b. Akiu chi mei chi na tiao yu?

Akiu eat not eat that CL fish

'Did Akiu eat that fish?'

This A-not-A formation can be applied to the resultative sequence [Vpri-V-Asp], but not the depictive sequence [V-Vpri-Asp], as shown in the contrast between the depictive constructions in (73) and the resultative constructions in (74):

(73) a. Akiu sheng chi le na tiao yu.

Akiu raw eat PRF that CL fish

'Akiu ate that fish raw.'

b. *Akiu sheng (chi) mei sheng chi na tiao yu?

Akiu raw eat not raw eat that CL fish

b'. *Akiu sheng chi-mei-chi na tiao yu?

Akiu raw eat-not-eat that CL fish

c. *Akiu huo (zhuo) mei huo zhuo na tiao yu?

Akiu alive catch not alive catch that CL fish

d. *Akiu nu (ma) mei nu ma Baoyu?

Akiu angry scold not angry scold Baoyu

(74) a. Akiu da po le na ge huaping.

Akiu beat broken PRF that CL vase

'Akiu beat that vase broken.'

b. Akiu da (po) mei da po na ge huaping?

Akiu beat broken not beat broken that CL vase

'Did Akiu break that vase?'

One account for this contrast is that the depictive sequence [V-Vpri-Asp] is derived at $\mathrm{PF}$, and thus there is no way to go back to syntax to integrate a [Q] feature into this sequence. The theoretical presupposition here is that any element which has been targeted by a phonological operation cannot undergo a subsequent syntactic operation. It is generally assumed that Chinese verbs overtly adjoin to the head of AspP in syntax to derive the verbasp sequence. I propose that depictive predicate verbs PF-adjoin to the left of the Vpri after the Vpri has moved to Asp. By the proposed PF movement, the depictive predicate verb leftadjoins to the sequence [Vpri-Asp], and thus a new sequence of [V-Vpri-Asp] is derived. In (73a), for instance, the lexical head sheng 'raw' of the depictive predicate moves from a VP to the head of a vP in syntax (8b) (step (1) in (75)), and the vP merges with the primary predicate as an adjunct (I use $\Rightarrow$ to show this adjunction integration in step (2) in (75)). The exact adjunction place is irrelevant here. On the other hand, in the structure of the primary predicate, $c h i$ 'eat' adjoins to the perfect aspect le in syntax, deriving [chi-le] at Asp (step (3) in (75)). Then at PF sheng moves from $v$ to [chi-le], deriving [sheng-chi-le] (step (4) in (75)).

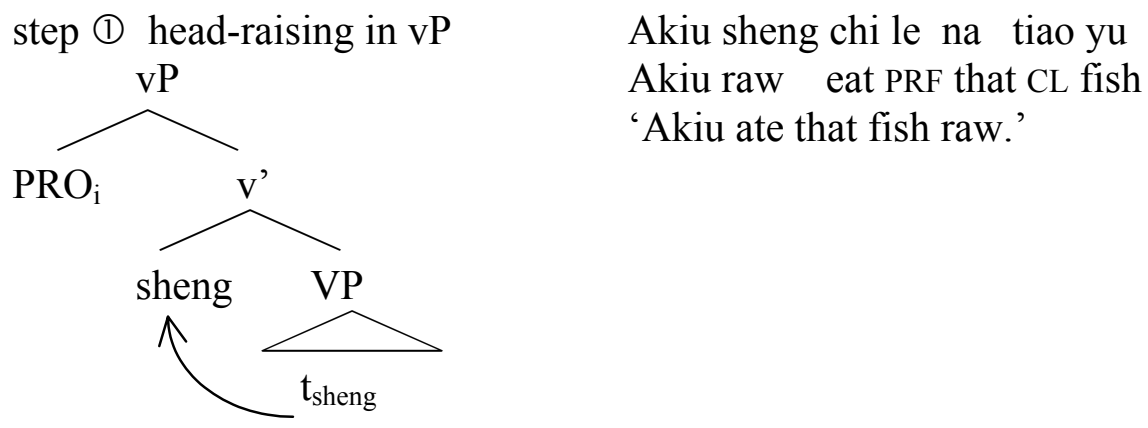


step (2) adjunction

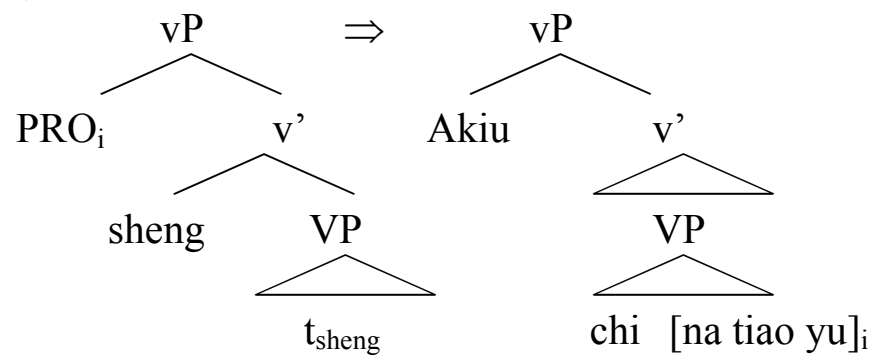

step (3) head-raising to Asp

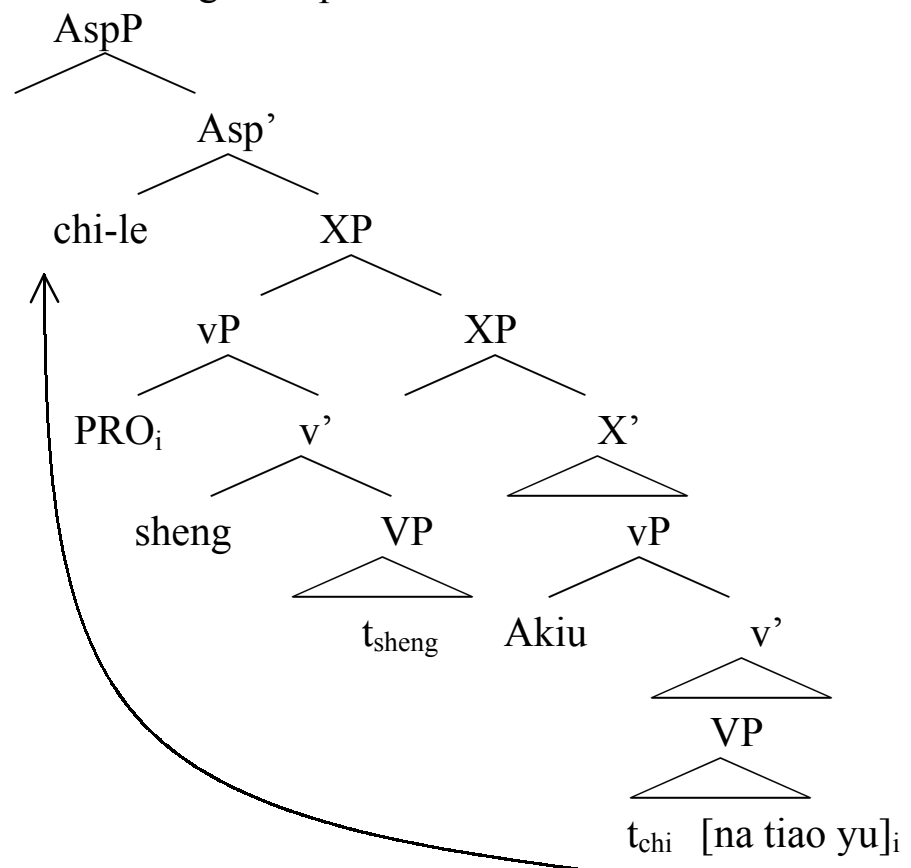

step (4) PF-raising

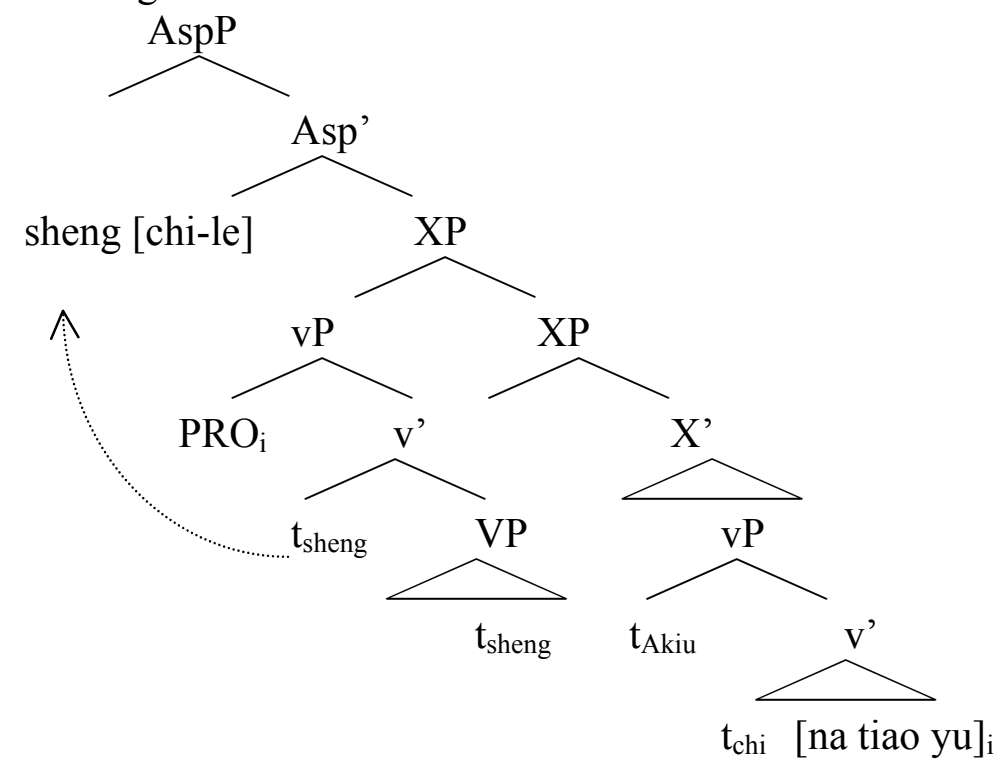

In this derivation, after sheng is combined with [chi-le] at PF, the derived form shengchi-le is opaque to any syntactic operation such as the integration of [Q] to derive an A-not-A form. Thus data like (73b-d) are underivable, as desired. In addition, being a PF operation, the raising of sheng from an adjunct in step (4) is not ruled out by CED. 
The resultative V-V construction, in contrast, does not involve any such PF operation. I illustrate the derivation of (74a) in (76). I assume that in this construction, after the resultative predicate verb po 'broken' raises to $\mathrm{v}(8 \mathrm{~b})$ (step (1)), the verb moves further to the right of the Vpri $d a$ 'beat', which selects the vP (step (2). ${ }^{10}$ Then the newly formed [da-po] raises to Asp, deriving the sequence of [da-po-le] (step (3)).

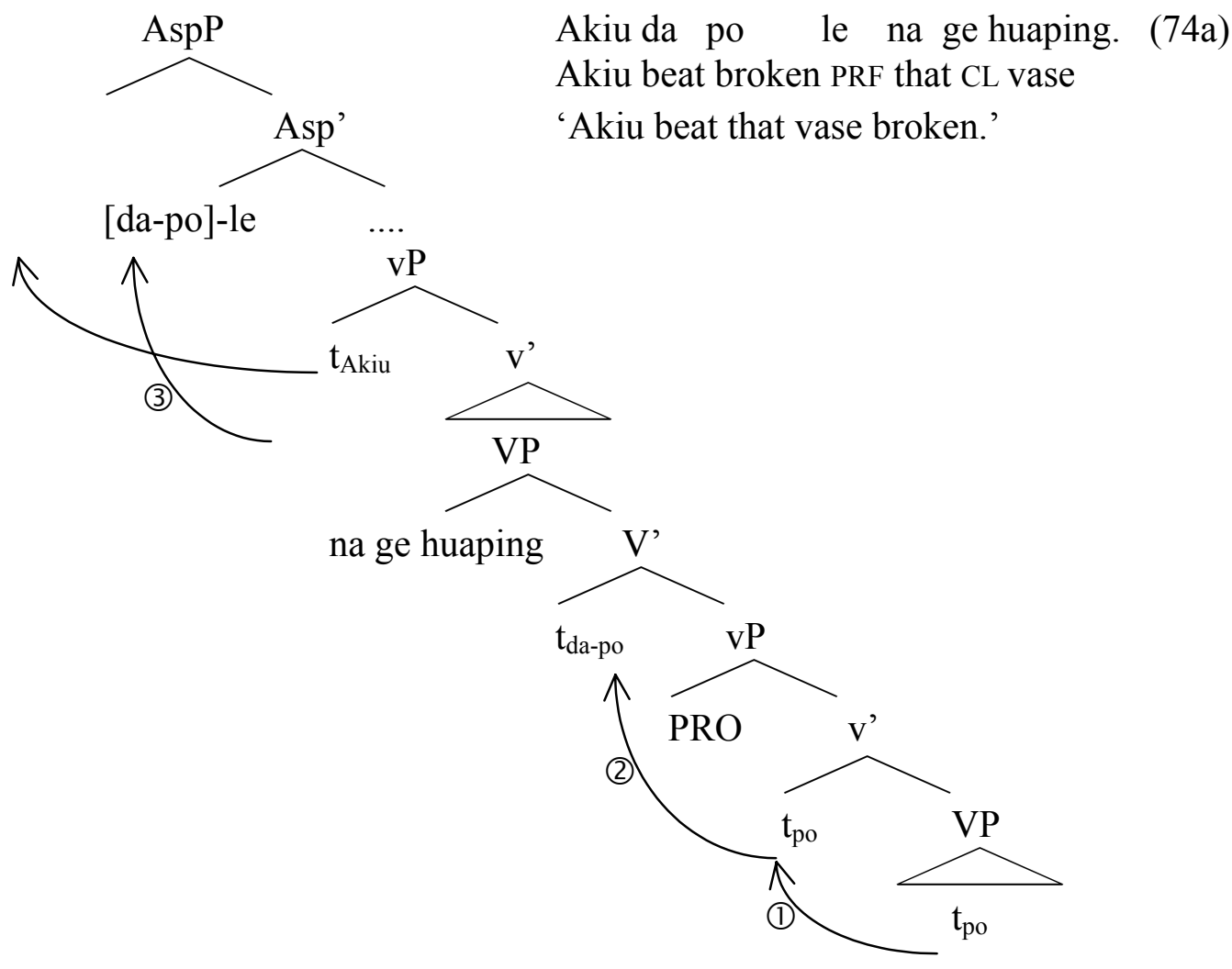

Since these three instances of head raising all occur in syntax, a further syntactic operation such as the integration of [Q] is possible. Thus this analysis captures the grammaticality of (74b).

\subsection{The DE Constructions}

In the depictive $d e$ construction, $d e$ is right-adjacent to the depictive predicate. This is shown in (77a), where the possible positions of the adverb like 'immediately' illustrate the adjacency.

a. Akiu (like) gaoxing (*like) de (like) na le yi zhang tanzi. A. immediately happy immediately DE immediately take PRF one CL carpet 'Akiu (immediately) took a carpet happy.'

b. Akiu hen gaoxing de ruanruan de zai di-shang pu le yi zhang tanzi. Akiu very happy DE soft DE at floor-on spread PRF one CL carpet 'Akiu spread a carpet on the floor soft happy.'

In (77a), de occurs to the immediate right of the depictive predicate gaoxing 'happy'. In (77b), there are two depictive predicates. Each occurrence of de surfaces to the right of each depictive predicate, hen gaoxing 'very happy' and ruanruan 'soft'. Data like (77) tell us that $d e$, which is base-generated at $\mathrm{v}$, surfaces to the immediate right of a depictive predicate.

\footnotetext{
${ }^{10}$ Kayne's (1994) constraint that heads can only left-adjoin to other heads is violated in this case. Other cases of similar violation can be found in the literature (cf. Roberts 2000). I leave this issue for future research.
} 
We have assumed that depictive predicates are complement of v (8a). In addition, we also assume that a complement is to the right of its selecting head (Kayne 1994). Thus the base-order of a depictive predicate in the de construction should be [de-X], where $\mathrm{X}$ is the depictive predicate. The surface order in (77), however, is [X-de].

In the resultative de construction, de is right-adjacent to Vpri. This is shown in (78), where the possible positions of the adverb yijing 'already' illustrate the adjacency.

Akiu (yijing) ku (*yijing) de liang tiao shoujuan dou shi le.

Akiu already cry already DE two CL handkerchief even wet PRT

'A. (already) cried so much that two handkerchieves were wet.'

In (78), de is immediately right-adjacent to the Vpri $k u$ 'cry', and no adverb can occur between the Vpri and de.

The de-cluster in both the depictive and the resultative construction fails to form an Anot-A form: ${ }^{11}$
a. Akiu rere de he le na bei cha.
Akiu hot DE drink PRF that cup tea
'Akiu drank that cup of tea hot.'
b. *Akiu rere de $\{\mathrm{mei} / \mathrm{bu}\}$ rere de he (le) na bei cha?
Akiu hot DE not/not hot DE drink PRF that cup tea
c. *Akiu rere de he $\{\mathrm{mei} / \mathrm{bu}\}$ he na bei cha?
a. Akiu da de Baoyu haotaodaku.
Akiu beat DE Baoyu cry.loudly
'Akiu beat Baoyu and as a result Baoyu cried loudly.'
b. *Akiu da de $\{$ mei/bu $\}$ da de Baoyu haotaodaku?
Akiu beat DE not/not beat DE Baoyu cry.loudly
c. *Akiu da $\{\mathrm{mei} / \mathrm{bu}\}$ da de Baoyu haotaodaku?

The impossibility of the de-clusters to have an A-not-A form suggests that they have undergone some PF operation and thus are opaque to the syntactic integration of [Q].

In addition, the Vpri in the depictive de construction can have an aspect suffix, as shown by the presence of le in (79a), whereas the Vpri in the resultative de construction cannot have an aspect suffix:
Akiu da $(* l e)$ de $(* l e)$ Baoyu haotaodaku.
Akiu beat PRF DE PRF Baoyu cry.loudly
'Akiu beat Baoyu and as a result Baoyu cried loudly.'

If the de-clusters are formed in PF, this aspect contrast can be accounted for. Specifically, I propose that de surfaces to the immediate right of the leftmost verbal lexical element of the construction, by a PF movement. The leftmost verbal lexical element is the Vpri in resultative constructions, whereas it is the depictive in depictive constructions. In (79a), for instance, the leftmost verbal element is rere 'hot', and thus de attaches to the right of rere. If so, after the PF movement, the opaqueness of the de-clusters to any syntactic

\footnotetext{
${ }^{11}$ One might argue that $(79 b)$ is not acceptable because rere 'hot' is not a typical verb and thus cannot have an A-not-A form. However, elements which do not look like typical verbs can have an A-not-A form. The preposition cong 'from' in (i) and the adjective-like word piaoliang 'pretty' in (ii) are both in A-not-A form:
(i) ta cong-mei-cong Shanghai lai?
s/he from-not-from Shanghai come
(ii) ta zhang de piaoliang-bu-piaoliang? s/he grow DE beautiful-not-beautiful 'Is s/he beautiful?'


operations such as the integration with [Q] to form an A-not-A form in (79) and (80) and raising of Vpri to Asp (81) is expected.

On the other hand, in the depictive construction, de attaches to the depictive predicate, rather than the Vpri, thus Vpri is free to undergo the syntactic movement to Asp. In contrast, in the resultative construction, de attaches to Vpri, making the latter unable to undergo the syntactic movement to Asp. ${ }^{12}$

In this research I adopt Chomsky's $(1998,1999)$ proposal that structure is sent to PF at discrete junctures in the derivation, called "phases." Chomsky argues that $\mathrm{CP}$ and vP are such phases. In resultative constructions, the $\mathrm{vP}$ which hosts the resultative is firstly merged with Vpri. Then in a certain step of the syntactic computations, Vpri moves to the left of its object, deriving the $\mathrm{VO}$ order, before a higher $\mathrm{vP}$ is built. After the derivation reaches to the level of the higher vP, a phase is completed. Then the vP is sent to PF. In PF, de moves from the lower $\mathrm{v}$ to the right of the leftmost verbal element, i.e., Vpri. Assume that AspP is projected higher than $\mathrm{vP}$. After the Vpri is targeted by the PF operation, there cannot be any aspect licensing relation between the Vpri and Asp in syntax any more (81). Nor can the Vpri merge with [Q] (80). The derivations of (80a) are illustrated in (82):

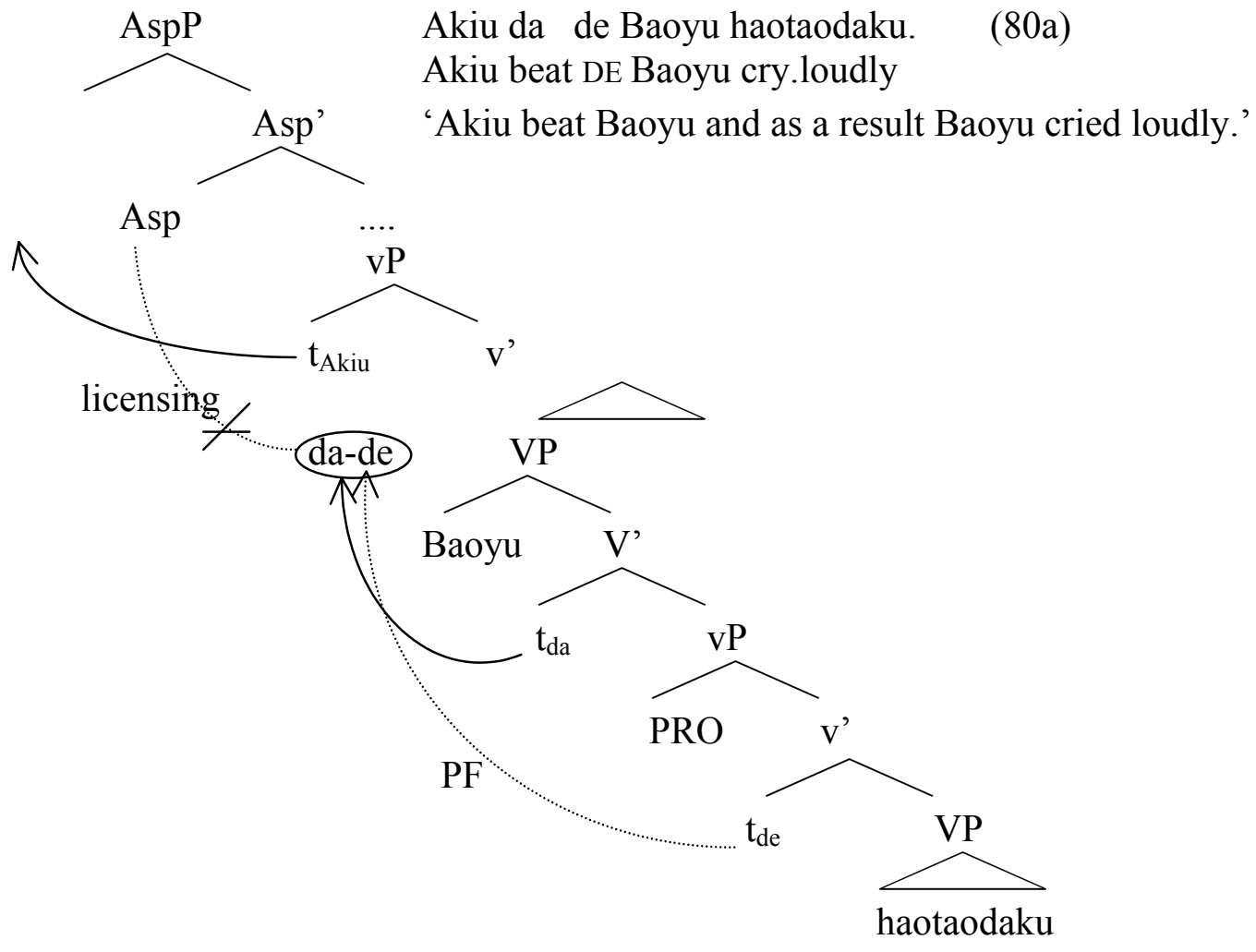

In contrast to the derivations in (82), if there is no PF-operation, the element in $\mathrm{v}$ is at the "edge" of the vP phase, so it may raise to Asp in the CP-phase. This is exactly what we see in the $\mathrm{V}-\mathrm{V}$ resultative construction, where the sequence of $\mathrm{V}-\mathrm{V}$-asp occurs.

\footnotetext{
${ }^{12}$ It has been suggested to me that a verb cannot have two suffixes in Chinese, and thus the constraint that Vpri does not have an aspect suffix in the de resultative construction should be covered. However, data like (i) show that a verb can have two suffixes, and thus the number of suffixes cannot account for the constraint:

(i) Akiu chi guo le fan jiu shuijiao le.

Akiu eat EXP PRF meal then sleep PRF

'After Akiu had eaten the meal, he slept.'
} 
In this section, I have argued that de attaches to the right of the leftmost verbal lexical element at PF. I have also argued that in the V-V construction, a depictive predicate PFadjoins to Vpri, whereas a resultative predicate undergoes a successive head-raising in syntax.

\section{The effect of head movement in resultative constructions}

The assumed successive head raising of the resultative predicate in the $\mathrm{V}-\mathrm{V}$ resultative construction, and the absence of the raising in the de resultative construction, explain the contrasts in the orientation of the resultative predicates and the specificity of the subject of the resultative predicates of the two constructions.

\subsection{The orientation of resultative predicates}

One contrast between the V-V and the de construction is that if the Vpri is not a subjectcontrol verb (see section 3.4.2), in the presence of an overt object of the Vpri, the V-V construction allows a subject-orientation reading, as noted by $\mathrm{Li}$ (1990), while the deconstruction does not, as shown in (83) and (84): $:^{13}$

a. Baoyu zhui lei le Daiyu.

Baoyu chase tired PRF Daiyu

'Baoyu chased Daiyu and as a result Daiyu got tired.'

'Baoyu chased Daiyu and as a result Baoyu got tired.'

b. Baoyu zhui de Daiyu qichuanxuxu.

Baoyu chase DE Daiyu gasp

'Baoyu chased Daiyu and as a result Daiyu gasped.'

a. Baoyu kan ni le na pan luxiang.

Baoyu watch fed.up PRF that CL video

'Baoyu watched that video and as a result he got fed up with it.'

b. *Baoyu kan de na pan luxiang dou ni le.

Baoyu watch DE that CL video even fed.up PRF

In the $\mathrm{V}-\mathrm{V}$ construction (83a), the subject of the resultative predicate is co-referential with either the subject or the object of Vpri, i.e., either Baoyu or Daiyu got tired. However, in the de construction ( $83 \mathrm{~b}$ ), the subject of the resultative predicate can only be co-referential with the object of Vpri, i.e., only Daiyu gasped, not Baoyu. In the V-V construction (84a), the subject of the resultative predicate is co-referential with the subject of Vpri, i.e., Baoyu got fed up. It cannot be co-referential with the object of Vpri, since semantically, na pan luxiang 'that video' cannot the subject of the predicate $n i$ 'get fed up'. In the de construction (84b), the subject of the resultative predicate cannot co-referential with the subject of Vpri. It can only be co-referential with the object of Vpri. However, since the semantic clash mentioned above rules out the co-indexing, the secondary predication fails and the sentence is unacceptable.

We have argued in section 3.4.2 that TRCs have a control structure. The control of the PRO subject of the resultative predicate by the subject of Vpri seems to violate MDP, since the nearest overt c-commanding nominal is the object of Vpri, rather than the subject of Vpri. Why is this violation allowed in the $\mathrm{V}-\mathrm{V}$ construction, but not in the de construction? ${ }^{14}$

\footnotetext{
${ }^{13}$ The subject of the primary predicate of (83) can also be a theme causer. In that case, it patterns with (15), and the reading of the sentence is 'Chasing Baoyu, Daiyu got tired.' See the discussion of (15) in section 2.1.

${ }^{14}$ It has been mentioned to me that Igbo also has the V-V resultative construction, however, we have not seen any subject-oriented reading in the language. It is unclear to me whether Igbo really does not allow a subjectorientated reading or simply we do not have such data available. In all the Igbo data in Dechaine (1993), such a reading is semantically or pragmatically ruled out. In any case, I leave this issue for future research.
} 
In Huang's (1992: 130) approach, the V-V construction is derived by a reanalysis of the complex predicate $\mathrm{V}^{\prime}$ into $\mathrm{V}^{0}$, and the raising of the entire compound. He claims that the essential difference between the V-V construction and the de-construction is that "whereas the former is a lexical category, the latter is a phrase" (p. 126). Consequently, the reading contrast like that between the a-sentences and the b-sentences in (83) and (84) is simply acknowledged by the claim that "the internal structures of compounds are not accessible to rules or principles that apply in syntax, in particular the MDP" (p. 127). Since in my approach, the $\mathrm{V}-\mathrm{V}$ construction is derived in syntax, an alternative account for the contrast is called for.

I have argued that a successive head-raising occurs in the V-V TRC, but not in the deTRC. Consider the structure (85), where $t$ is the trace of $Y$, which is adjoined to $X$ to form [Y-X].

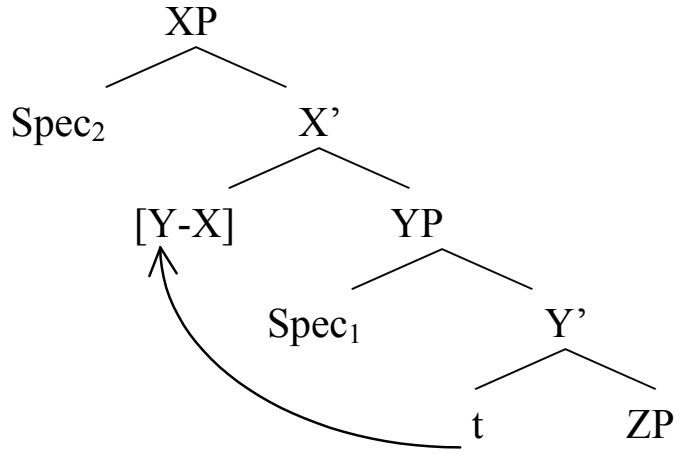

Chomsky (1993, 1995: 298) claims that in this structure $\mathrm{Spec}_{1}$ and $\mathrm{Spec}_{2}$ are both in the minimal domain of the chain Y-t and are therefore equidistant from $\alpha$, which is either ZP or a nominal within ZP. Move can therefore raise $\alpha$ to target either $\mathrm{Spec}_{1}$ or $\mathrm{Spec}_{2}$, which are equally close to $\alpha$. It is reasonable to extend the application of this notion of equidistance from movement to control (in Hornstein 1999, 2001 control is analyzed as an operation of theta-to-theta movement). Accordingly, let us assume that in the V-V TRC, the successive head raising makes the subject of the Vpri and the object of the Vpri equidistant from the PRO subject of the resultative. In contrast, in the de-TRC, no corresponding successive head raising occurs in syntax, and thus compared to the subject of the Vpri, the object of the Vpri is always closer to the PRO subject of the resultative. Although some technical details need to be worked out, it is reasonable to claim that head raising in syntax may allow some control cases to escape from the constraint of MDP.

\subsection{The specificity of the subject of resultative predicates}

Another contrast between the de and the V-V TRC is that the subject of the resultative predicate in the former cannot be nonspecific, like a regular subject in Chinese generally, whereas the subject of the resultative predicate in the latter can. The contrast is shown in (86):

a. Akiu da de $\{$ na/*yi $\}$ ge xiaohair haotaodaku.

Akiu beat DE that/one CL child cry.loudly

'Akiu beat that child and as a result the child cried loudly.'

b. Akiu da ku le yi ge xiaohair.

Akiu beat cry PRF one CL child

'Akiu beat a child and as a result the child cried loudly.'

Tsai (2001) argues that head-raising out of the projection where a subject is basegenerated can license a non-specific reading of the subject. In the above discussion we have claimed that in the $\mathrm{V}-\mathrm{V}$ resultative construction, the resultative predicate first raises from VP to the lower $\mathrm{v}$, it then raises from the lower vP to Vpri, and finally the derived [Vpri-V] raises 
to Asp (passing the higher v). In the second step of the head chain, the resultative predicate moves out of the vP where the subject of the predicate, a PRO, is base-generated. If Tsai's basic thesis is right, a nonspecific reading of the subject of the resultative predicate in this case is licensed. In contrast, in the de resultative construction, the resultative predicate never moves out of the lower $\mathrm{vP}$, where its subject, a PRO, is base-generated, and thus no nonspecific reading of the subject is licensed in TRC (however the Case relation of the subject of a resultative with the Vpri makes possible the nonspecific reading of the subject in IRC. See section 3.4.3).

In this section I have argued that in the V-V TRC, the successive head-raising may account for the possible subject-oriented reading of the resultative predicate, and the head raising out of the lower vP can account for the possible non-specific reading of the subject of the secondary predicate.

\section{Conclusions and remaining issues}

I have argued for the projection of $\mathrm{vP}$ in secondary predication. In secondary predication, $\mathrm{v}$ is overtly realized in Chinese by Merge (insertion of the functional word de) or Move (attraction of the lexical head of a secondary predicate). The former option derives the de-construction, whereas the latter option derives the $\mathrm{V}-\mathrm{V}$ construction. I have also presented the asymmetry between $\mathrm{vP}$ as a complement of Vpri and $\mathrm{vP}$ as an adjunct of the structure of the primary predication. Specifically, resultatives are hosted by complement vPs, whereas depictives are hosted by adjunct vPs. This complement-adjunct asymmetry accounts for a series of syntactic properties of secondary predication in Chinese: the position of a secondary predicate with respect to Vpri, the co-occurrence patterns of secondary predicates, the hierarchy of depictives, the control and ECM properties of resultative constructions, and the locality constraint on the integration of secondary predicates into the structure of primary predication.

In addition, I also argued that the surface position of $d e$ is derived by a PF operation which attaches de to the right of the leftmost verbal lexical head of the construction, and that in the V-V TRC, the successive head-raising may account for the possible subject-oriented reading of the resultative predicate, and that the head raising out of the lower vP accounts for the possible non-specific reading of the subject of the resultative predicate.

In this paper we have analyzed two properties of Chinese secondary predicate constructions which are not found in English: the alternation of the de and the V-V constructions, and the possible subject-oriented reading of resultatives under a certain syntactic condition, i.e. in the V-V construction. There is a third difference between the two languages which has not been noted in the literature: the occurrence of an overt subject of a secondary predicate in the presence of both subject and object of Vpri:
a.
na zhi laohu xue linlin de chi le yi kuai rou. that CL tiger blood drip DE eat PRF one chunk meat
'That tiger ate a chunk of meat with dripping blood.'
b. Baoyu $\mathrm{t}_{\mathrm{i}} \mathrm{da}$ de Daiyu [ $\underline{\mathrm{shou}}$ dou teng le $]$ ].
$(\text { resultative })^{15}$
Baoyu beat DE Daiyu hand also painful PRT

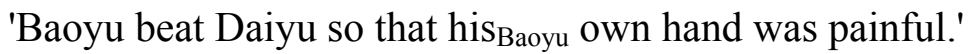

\footnotetext{
${ }^{15}$ I thank Zo Xiu-Zhi Wu for helping me with the Chinese example (87b). Korean data similar to (87) can be found in Kim \& Maling (1997).
} 
In (87a), xue 'blood' is the subject of the depictive linlin 'drip', and it has a theta relation with the depictive, rather than with the Vpri chi 'eat', which has both the overt subject Akiu and the overt object yi kuai rou 'one chunk meat'. Similarly in (87b) there is no argument sharing between the overt two arguments of the Vpri and the overt subject of the resultative predicate. In this sentence, shou 'hand' is the subject of the resultative teng 'painful', and it is co-referential with neither of the two overt arguments of the Vpri $d a$ 'beat', Baoyu and Daiyu. Unlike the English sentence in (88), there is no intonation break between the part which denotes the secondary predication and the rest of the sentence. Thus data like (87) look like regular secondary predication constructions.

John left, his ears red.

Data like (87), however, have two constraints. First, the overt subject of the secondary predicate must have a part-whole relation with an argument of the Vpri. In (87a), xue 'blood' is the subject of the depictive linlin 'drip', and it has a part-whole relation with the object of the Vpri, yi kuai rou 'one chunk meat'. (89a) is not acceptable, because there is no part-whole relation between the overt subject of the depictive, tian 'sky', and any argument of the Vpri. In (87b), the subject of Vpri, Baoyu, is an inalienable possessor of shou 'hand', which is the subject of the secondary predicate teng 'painful'. (89b) is unacceptable because no such relation occurs between the subject of the secondary predicate, caidao 'knife', and any argument of the Vpri.
a. *na zhi laohu tian hei de chi le yi kuai rou. that CL tiger sky dark DE eat PRF one CL meat
b. *Akiu qie de rou caidao dou dun le. Akiu cut DE meat knife even blunt PRF

The second constraint is that between the two nominals which have a part-whole relation, the overt argument of Vpri and the overt subject of a secondary predicate, it is always the case that the former is an inalienable possessor of the latter. This relation cannot be reversed. These two constraints suggest that a kind of possessor-raising may occur in such data from the $\mathrm{vP}$ which hosts the secondary predicate to the structure of primary predication, or that a kind of possessee-possessor dependency construal occurs between an argument of vP which hosts the secondary predicate and an argument of Vpri. Such data may reveal the extent of grammatical argument-sharing, which has been claimed to be a defining property of depictive (Rothstein 2000a). I leave this for future research.

\section{References}

Arnold, M. D. 1995 Case, Periphrastic Do and the Loss of Verb Movement in English. PhD dissertation, University of Maryland, College Park.

Bach, E. 1979 Control in Montague Grammar. Linguistic Inquiry 10, 515-531.

Bowers, J. 1993 The syntax of predication. Linguistic Inquiry 24, 591-656.

Bowers, J. 1997 A binary analysis of resultatives. Texas Linguistics Forum 38, 43-58.

Bowers, J. 2000 Predication. M. Baltin \& C. Collins (eds.) The Handbook of Contemporary Syntactic Theory. Blackwell. 299-333.

Carrier, J. \& J. Randall 1992 The argument structure and syntactic structure of resultatives. Linguistics Inquiry 23, 173-234.

Cheng, L. 1997 Resultative compounds and lexical relational structures. Chinese Languages and Linguistics III, 167-197.

Chomsky, N. 1957 Syntactic Structures. Mouton. \& Co.'S-Gravenhage.

Chomsky, N. 1993 A minimalist program for linguistic theory. In K. Hale and S. J. Keyser (eds.) The View from Building 20: Essays in Linguistics in Honor of Sylvain Bromberger, 1-52. Cambridge MA: MIT Press.

Chomsky, N. 1995 Categories and transformation. In The Minimalist Program, 219-394. Cambridge, Mass.: MIT Press.

Chomsky, N. 1998 Minimalist Inquiries: the Framework. Ms. MIT. 
Chomsky, N. 1999 Derivation by Phase. MIT Occasional Papers in Linguistics 18.

Chung, Y. 2001 Against the two types of tough gaps: a response to Jacobson. Snippets 3, 8-9.

Dechaine, R-M. 1993 Predicates Across Categories: Towards Category-neutral Syntax. Doctoral Dissertation. University of Massachusetts, Amherst.

den Dikken, M. \& R. Sybesma 1998 Take Serials Light up the Middle. Paper presented at GLOW 21, Tilburg University, 15 April 1998.

Diesing, M. 1992 Indefinites, MIT Press, Cambridge, MA.

Hoekstra, T. 1988 Small Clause Results. Lingua 74, 101-139.

Hornstein, N. 1999 Movement and Control, Linguistic Inquiry 30, 69-96.

Hornstein, N. 2001 Move! A Minimalist Theory of Construal. Blackwell, Massachusetts.

Hornstein, N. \& D. Lightfoot 1987 Predication and PRO. Language 63: 23-52.

Huang, J. 1992 Complex Predicates in Control. In J. Higginbotham and R. Larson (eds.), Control and Grammar, Kluwer, Dordrecht, 109-147.

Huang, J. 1994 Verb movement and some syntax-semantics mismatches in Chinese. Chinese Languages and Linguistics II, 587-613.

Huang, J. 1997 On lexical structure and syntactic projection. Chinese Languages and Linguistics III, 45-89.

Kayne, R. 1994 Antisymmetry of syntax. MIT Press, Cambridge MA.

Kim, S. \& J. Maling 1997 A crosslinguistic perspective on resultative formation. Texas Linguistics Forum 38, 189-204.

Koizumi, M. 1994 Secondary Predicates. Journal of East Asian Linguistics 3, 25-79.

Kratzer, A. 1994 On External Arguments. University of Massachusetts Occasional Papers 17: 103-130.

Larson, R. 1991a. Some issues in verb serialization. Serial verbs: grammatical, comparative and cognitive approaches, edited by C. Lefebvre, 185-210. John Benjamins, Amsterdam.

Larson, R. 1991b. Promise and the theory of control. Linguistics Inquiry 22, 103-140.

Levin, B. and M. Rappaport Hovav 1995 Unaccusativity: At the Syntax-Lexical Semantics Interface. Cambridge, Mass: MIT Press.

Li, A. 1999 Minimal $\alpha$. Paper presented at DGfS 21, Konstanz, February 24.

Li, C. \& S. Thompson 1981 Mandarin Chinese: a functional reference grammar. University of California Press, Berkeley/Los Angeles.

Li, Y. 1990 On V-V compounds in Chinese. Natural Language and Linguistics Theory 8, 177-207.

Li, Y. 1998 Chinese Resultative Constructions and the Uniformity of Theta Assignment Hypothesis. In: J. Packard (ed.) New Approaches to Chinese Word Formation. Mouton de Gruyter, Berlin, 285-310.

Li, Y. 1999 Cross-componential causativity. Natural Language and Linguistic Theory 17: 445-497.

Marantz, A. 1997 No escape from syntax: don't try morphological analysis in the privacy of your own lexicon. U. Penn Working Papers in Linguistics, 4-2, 201-225.

McConnell-Ginet, S. 1982 Adverbs and logical form: a linguistically realistic theory. Language 58, 144-184.

Nishiyama, K. 1998 V-V Compounds as Serialization. Journal of East Asian Linguistics 7, 175-217.

Nunes, J. 1995 The copy theory of movement and lineraization of chains in the minimalist program. Ph.D. dissertation, University of Maryland at College Park.

Nunes, J. and J. Uriagereka 2000 Cyclicity and extraction domains. Syntax 3, 20-43.

Roberts, I. 2000 Head movement. M. Baltin \& C. Collins (eds.) The Handbook of Contemporary Syntactic Theory. Blackwell. 113-147.

Rosenbaum, P. 1970 A Principle Governing Deletion in English Sentential Complementations. In R. Jacobs and P. Rosenbaum (eds.) Readings in English Transformational Grammar, Ginn, Waltham, MA, 20-9.

Rothstein, S. 1985 The syntactic forms of predication. Ph. D. dissertation. MIT.

Rothstein, S. 1992 Case and NP licensing. Natural Language and Linguistic Theory 10, 119-139.

Rothstein, S. 2000a Secondary predication and aspectual structure. ZAS Papers in Linguistics 17, $242-264$.

Rothstein, S. 2000b Deriving restrictions on resultatives: incrementality, culminations, and result states. Paper presented at the Workshop on Predicative Constructions, ZAS, Berlin, Oct. 16-17.

Simpson, J. 1983 Resultatives. L. Levin, M. Rappaport and A. Zaenen (eds.) Papers in Lexical-Functional Grammar, 143-157. Bloomington, Indiana University Linguistics Club.

Sybesma, R. 1999 The Mandarin VP. Kluwer Academic Publishers: Dordrecht.

Tsai, W. 2001 On Subject Specificity and Theory of Syntax-Semantics Interface. Journal of East Asian Linguistics 10, 129-168.

Wilder, C. 1991 Small Clauses and Related Objects. GAGL 34, 215-236.

Wilder, C. 1994 Small Clauses im Englischen und in der GB-Theorie. In A. Steube \& G. Zybatow (eds.) Zur Satzartikeit von Infinitiven und Small Clauses. Niemeyer, Tübingen. 219-241.

Williams, E. 1980 Predication. Linguistic Inquiry 11, 203-238.

Winkler, S. 1997 Focus and secondary predication. Mouton de Gruyter, Berlin-New York.

Zou, K. 1994 Resultative V-V Compounds in Chinese. MIT Working Papers in Linguistics 22, 271-290. 